\title{
Acute spinal cord injury: Pathophysiology and pharmacological intervention (Review)
}

\author{
YI ZHANG ${ }^{1,2^{*}}$, ABDULLAH AL MAMUN $^{2 *}$, YUAN YUAN $^{2}$, QI LU ${ }^{2}$, JUN XIONG $^{2}$, \\ SHULIN YANG ${ }^{1}$, CHENGBIAO WU $^{2}$, YANQING WU ${ }^{3}$ and JIAN WANG ${ }^{4}$

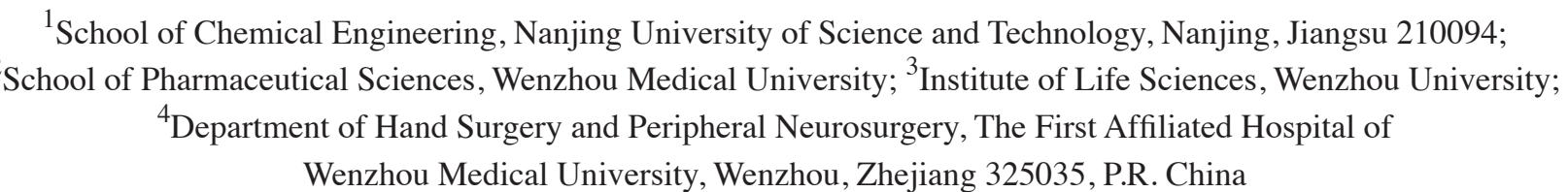

Received April 4, 2020; Accepted November 12, 2020

DOI: $10.3892 / \mathrm{mmr} .2021 .12056$

\begin{abstract}
Spinal cord injury (SCI) is one of the most debilitating of all the traumatic conditions that afflict individuals. For a number of years, extensive studies have been conducted to clarify the molecular mechanisms of SCI. Experimental and clinical studies have indicated that two phases, primary damage and secondary damage, are involved in SCI. The initial mechanical damage is caused by local impairment of the spinal cord. In addition, the fundamental mechanisms are associated with hyperflexion, hyperextension, axial loading and rotation. By contrast, secondary injury mechanisms are led by systemic and cellular factors, which may also be initiated by the primary injury. Although significant advances in supportive care have improved clinical outcomes in recent years, a number of studies continue to explore specific pharmacological therapies to minimize SCI. The present review summarized some important pathophysiologic mechanisms that are involved in SCI and focused on several pharmacological and non-pharmacological therapies, which have either been previously investigated or have a potential in the management of this debilitating injury in the near future.
\end{abstract}

Correspondence to: Dr Yanqing Wu, Institute of Life Sciences, Wenzhou University, Chashan Street, Wenzhou, Zhejiang 325035, P.R. China

E-mail: yqwu220946@yeah.net

Dr Jian Wang, Department of Hand Surgery and Peripheral Neurosurgery, The First Affiliated Hospital of Wenzhou Medical University, Chashan Street, Wenzhou, Zhejiang 325035, P.R. China E-mail: jianwang0516@126.com

*Contributed equally

Key words: spinal cord injury, primary and secondary damage, systemic factors, local vascular effects, cyclooxygenase inhibitors, minocycline

\section{Contents}

1. Introduction

2. Pathophysiology of SCI

3. Pharmacological drugs used for the treatment of SCI

4. Non-pharmacological therapies for SCI

5. Conclusions

\section{Introduction}

Spinal cord injury (SCI) is caused by a degenerative loss of motor, sensory and autonomic function (1). As a result, trauma occurs either due to partial or complete damage to the spinal cord (2). It poses physical, psychosocial and vocational implications for patients and caregivers alike. SCI can therefore pose a threat to the health of the patient. Long-time treatment, cost of care and economic losses can affect the patients and their families, raising social and physiological issues. Typically, $>50 \%$ of patients may not regain their normal function and daily life (3). Healthy young individuals of 15-25 years are most commonly affected; because of this, SCI is a serious worldwide health concern (3). Extensive attempts for SCI treatment have so far been aimed at developing treatments for SCI effects (1). However, an active or permanent cure in the treatment of this condition has yet to be developed.

Central nervous system function cannot be regained following SCI and this is a crucial clinical concern (4). For a number of years, researchers and clinicians have been trying to determine various viable options based on the pathophysiology of SCI to improve neuronal function. This has led to efforts aimed at developing pharmacological treatments for SCI to reduce neuronal damage and improve neuronal function (5). Several pharmacological and non-pharmacological treatments show improvement or even recovery of motor functions and minimization of neurological damages $(2,6)$. In particular, preventing secondary injury, enhancing regeneration and replacing destroyed spinal tissue are the current primary aims to treat SCI (7). Additionally, some potential pharmacological candidates including mynocycline, are already being studied in clinical trials for the treatment of SCI (8). 


\section{Pathophysiology of SCI}

The mechanism of primary and secondary damage following $S C I$. Spinal cord compression is the most frequent mechanism of SCI and can continue after the injury (9). Penetrating injuries and strain to the neural tissues or vascular structures are caused by dislocation, flexion, extension or distraction forces related to rotation (9). Other mechanical damage to bone structures and ligaments can result, or consequences related to compression can give rise to hematomas in the spinal cord channel (10). Bleeding during spinal trauma begins during the early period of SCI and is later followed by the interruption of blood supply (11). Hypoxia and local ischemic infraction are both consequences of the disruption of blood flow following SCI (12). Specifically, these two conditions damage the grey matter, where metabolic function is high. Neurons in the damaged area are physically fractured and the myelin thickness is reduced (13). In addition, deterioration in neuronal transmission can be augmented by edema and the accumulation of macrophages in the damaged tissue (14).

Secondary damage can be initiated by primary damage, whereas a number of pathophysiological mechanisms can come into play even hours and days after developing SCIs (15). The most notable mechanism is a lack of energy due to ischemia and impaired perfusion at the cellular level (16). Ischemia can result immediately after traumatic SCI and, if left untreated, additional damage may commence within the first $3 \mathrm{~h}$ and continue for at least $24 \mathrm{~h}(8,17)$. Several crucial changes are found, such as hemorrhage, demyelination, edema, and cavity formation with axonal and neuronal necrosis, as well as a series of pathological changes in the nerve tissues following SCI, which can further increase infarction (18). High levels of glutamate can cause excitotoxicity, oxidative damage and ischemia, while $\mathrm{Ca}^{2+}$-dependent nitric oxide synthesis can cause secondary spinal cord damage $(19,20)$. Following secondary injuries, increased free radical damage and lipid peroxidation in the cell membrane and secondary injury signaling cascades at the injured tissue areas can eventually lead to neuronal death $(12,21)$.

Nevertheless, extensive experiments show that the spinal cord has excellent healing properties (22). Proper blood flow is an essential factor in ensuring that progressive tissue damage precedes and promotes necrosis during the healing process (23). SCI is therefore regarded as a pathological condition involving injury to the nerve tissue. Pathological cascades, ranging from atrophy to apoptosis or necrosis, can be result in the deterioration of neurons in the brain due to local injuries to the spinal cord (6). The axons in the injured area may be regenerated due to the well-vascularized astrocytic environment (24). Secondary injury may also cause neuronal death (25). Insight into the mechanisms of secondary damage can be useful in developing advanced therapies. Systemic and local effects contribute to the development of secondary damage (15).

Systemic factors. Systemic factors causing acute SCI include hypotension resulting from neurological shocks, minimized cardiac output and respiratory failure (9). In such cases, the supply of essential metabolites and oxygen to the nervous tissue is restricted. Low blood pressure must be promptly controlled in patients with spinal shock $(19,26)$. Since perfusion pressure is mainly related to systemic blood pressure, damage to the spinal cord is aggravated $(26,27)$. Hence, issues arising in the cardiopulmonary system are liable to increase the severity of SCI by damaging the spinal cord (18). Normal blood pressure must be maintained to avoid intramedullary hyperemia and hemorrhage (28). In addition, post-traumatic hypotension can occur following SCI and last for a few days or even months (29). In animal models, blood transfusion and dopamine can provide normotension, which can lead to an increase in blood flow to the spinal cord (23). However, since the local micro-circulation is affected, the functions of the spinal cord cannot be improved.

Inflammatory responses. Peripheral immune cells, including macrophages, neutrophils and $\mathrm{T}$ cells, can initiate an inflammatory response following SCI, which may gradually increase within a few days (22). Macrophages and neutrophils can cause the growth of lesions and lead to tissue damage (Fig. 1) (30). The release of inflammatory cytokines (TNF, IL-1, IL-6 and IL-10) and macrophages results in inflammatory reactions and subsequent pathological changes to the microglia (4). The lesion sites exhibit an increase in the levels of several inflammatory mediators including leukotrienes, bradykinin, prostaglandins, platelet-activating factors and serotonin (4). Central nervous system (CNS) inflammatory responses may be promoted by several cytokines, chemokines, oxygen, nitric oxide and other nitrogen-containing molecules (31). IL-10 is a neuroprotective cytokine and can improve motor function (32). The inflammation levels are significantly decreased in an animal model after 30 min of IL-10 administration (8).

Free radicals. The generation of free radicals should be inhibited to maintain cell viability (33). The activity of the endogenous antioxidant system is reduced by aging and has a substantial impact on SCI (34). Previous studies revealed that cyclosporin $\mathrm{A}$, vitamin $\mathrm{E}$ and selenium are effective in the management of SCI $(35,36)$. In addition, lipid peroxidation in SCI is inhibited by melatonin, mexiletine, thiopental and propofol $(34,37,38)$.

Excitatory amino acids. There is a direct influence of the excitatory neurotransmitter in the spinal cord by $N$-methyl-D-aspartate (NMDA) receptors (39). Studies reveal that blocking the NMDA receptor results in protection from secondary damage due to trauma and ischemia in animal models $(39,40)$. NMDA antagonists can significantly improve neurological functions and decrease the incidence of edema $(41,42)$. Magnesium ions can block the ion channels of the NMDA receptors (14). A previous study identified a reduction in the injured area and indicates that functional improvement can be achieved by the administration of $\alpha$-amino-3-hydroxy5-methyl-4-isoxazolepropionic acid (AMPA) antagonists (32). Glutamate is an important excitatory neurotransmitter located in the CNS. Neuronal damage occurs due to the overactivation of the glutamate receptors (43). Shortly following SCI, there is an increase in the levels of excitatory amino acids, including glutamate and aspartate (44). The extracellular excitatory amino acids reach toxic levels within 15 min of injury to the spinal cord and can last $\leq 120 \mathrm{~min}(45)$. 


\section{Mechanisms of Injury}
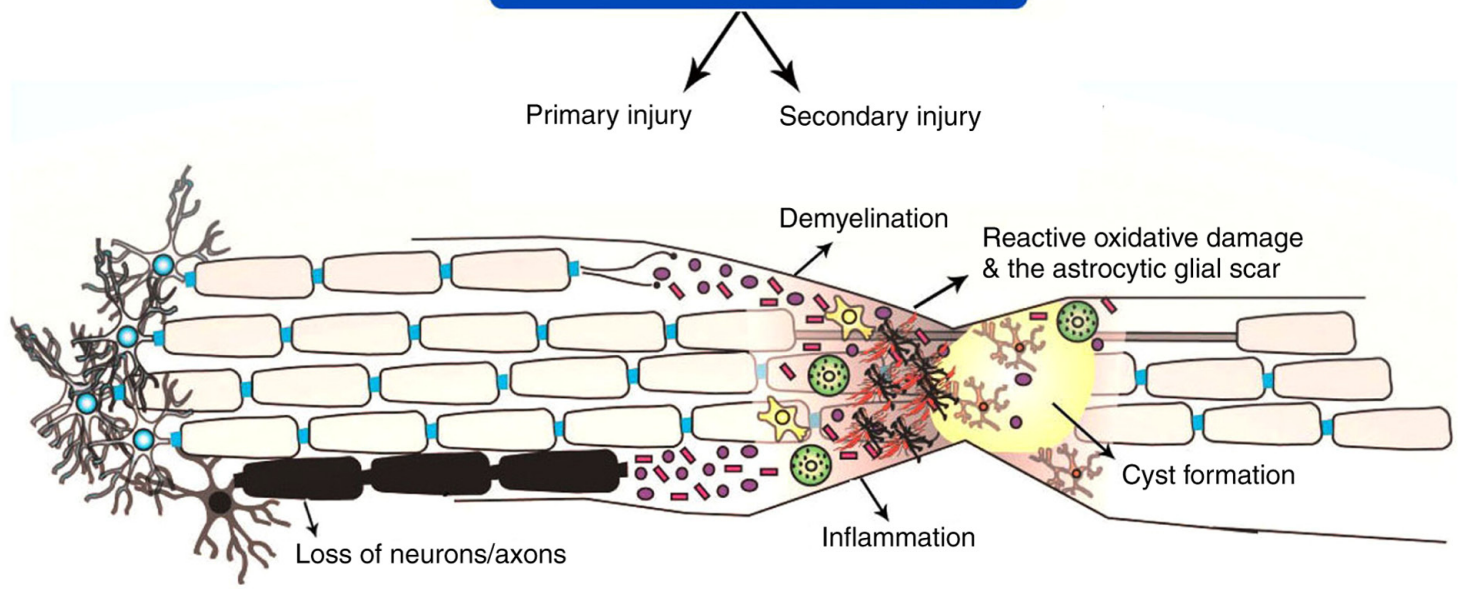

Figure 1. Pathophysiology of primary and secondary injury during spinal cord injury.

Apoptosis. Apoptosis is activated following SCI due to the release of inflammatory cytokines and free radicals, which lead to inflammation and excitotoxicity (46). Between $3 \mathrm{~h}$ and 8 weeks following SCI, apoptosis occurs in the areas surrounding the injured spinal cord tissue (47). Several studies indicate that after a few weeks of injury, demyelination is intensified by apoptosis of the oligodendrocytes $(47,48)$. David et al (48) report that oligodendrocytic changes occur in response to SCI. Furthermore, apoptosis adversely affects the situation by increasing neuronal loss. Other studies reveal that apoptosis results in deterioration of the microglia and enhances secondary inflammatory injury $(15,49)$. Previous studies also show that several caspase components are activated following SCI $(48,50)$. Several stimuli are known to activate three major apoptosis pathways through caspases (51). Apoptosis is induced in specialized cells, including neurons, astrocytes, oligodendrocytes and microglia (48). Therefore, neuronal protection is a crucial and challenging concern, as neurons in the spinal cord cannot be reproduced. Based on the regenerative ability of the glial cells, preventing glial death can enhance neuronal protection by two mechanisms (52). In the first mechanism, glial cells provide neurotrophic and metabolic support to the injured neurons to promote recovery (53). The second mechanism is based on the ability of glial cells to scavenge apoptotic mediators, including cytokines, and prevent the leak of free radicals from dying cells, which are toxic to the adjacent cells (54).

Opiate receptors. Opioid peptides are locally released during SCI (55). The hypothesis that endogenous opioids may have a significant role in the mechanism of secondary injury has been proven by previous studies that show that blocking the opiate receptors protects against cellular damage as well as preventing release of cellular contents $(56,57)$. Previous research also indicates that the administration of non-selective antagonists, such as naloxone, improves blood flow and clinical outcomes in patients following acute SCI (58-61).

Local vascular effects. Severe SCI causes a substantial decrease in blood supply, resulting in the initiation of ischemia following the trauma (62). When the spinal cord autoregulation is disrupted, abnormal changes in systemic hemodynamics may be reflected in blood flow in the spinal cord (63). Therefore, the ischemia produced by SCI is enhanced by systemic hypotension and hypoxia. The transportation of glucose and oxygen to tissues and ATP generation are substantially reduced due to ischemia (63). The exact cause of post-traumatic ischemia remains to be elucidated (2). However, focal narrowing of sulcal arterioles and intramedullary capillaries, fragmentation, aneurysmal dilatation or occlusion have been reported in experimental studies $(64,65)$. A study demonstrated progressive vascular damage in a spinal cord contusion injury model for the first time (66). The uptake of Evans blue increases by $\sim 76 \%$ in the injury area at $24 \mathrm{~h}$ compared with those at $2 \mathrm{~h}$ (67). Low $\mathrm{pH}$ of tissue due to lactic acidosis, as well as the accumulation of fibrin and platelets that cause congestion of venous stasis, may contribute to ischemia (68). In addition, ischemia is caused by the damaging of capillary endothelium, edema, petechial hemorrhages and vasoactive cytokines (69). Under these conditions, the systems adopt anaerobic respiration. Various pathophysiological processes can be affected by ischemia and activation of anaerobic respiration (70). Edema is formed at the injured area and around peripheral tissues due to proteinaceous leakage from intrinsic spinal cord veins (71). Spinal cord pressure is increased by edema and the disruption of blood flow of the spinal cord occurs (72). Magnesium can diminish edema and vascular permeability in SCI (71).

Abnormal changes in the concentration of electrolytes are observed following spinal cord trauma $(14,73,74)$. Formation of glutamate and free radicals is significantly increased due to ischemia-reperfusion injury (75). Antagonism of glutamate in endothelium can prevent the devastation of the blood spinal cord barrier. Evidence demonstrates that glutamate receptor blockers improve neurological results in SCI (60). Magnesium ions can decrease the lipid peroxidation process via the antagonism of glutamate receptors (76). Calcium ions can also serve a role in cell death, as calcium ions can activate phospholipases, proteases and phosphorylases in cells (77). Another experimental study reported that calcium channel blockers can significantly prevent secondary SCI (77). Extensive 
experimental studies suggest that blood flow to the spinal cord is improved by those agents, such as gacyclidine, which have significantly positive activity on healing $(18,77,78)$.

\section{Pharmacological drugs used for the treatment of SCI (Table I; Fig. 2)}

Cyclooxygenase (COX) inhibitors. COX inhibitors are a preferred choice for the treatment of SCI in the damaging secondary pathway (79). Ibuprofen and meclofenamate are two common non-steroidal anti-inflammatory drugs that can be applied to maintain spinal cord blood flow following SCI in an animal model $(80,81)$. The combination of a thromboxane inhibitor with a prostacyclin analogue shows a similar effect (82). In a rat model, COX-2 expression levels are greatly augmented in the injured spinal cord tissue following contusion injury and the pharmacological inhibition of COX-2 isoform enhances functional results in moderately acute spinal injuries $(80,83)$. Although the widespread use and clinical applications of COX-1 or COX-2 inhibitors for SCI in humans have not yet been indicated in the aforementioned previous studies, their wide use as well as application in the musculoskeletal and rheumatologic conditions assuages several of the safety and pharmacokinetics concerns.

Glutamate receptor antagonists. Activation of NMDA and non-NMDA can serve a crucial role in the excitotoxic damage following SCI (84). Along with traumatic disorders, non-traumatic CNS disorders have quickened the development of associated pharmacological interventions. NMDA-receptor antagonists, including MK801 and gacyclidine, demonstrate substantial neuroprotective effects following SCI in animal experiments (76). The development of NMDA-targeting systemic clinical therapies and applications has been impeded by the extensive distribution of glutamate and its receptor throughout the entire human CNS, which makes it a challenge to avoid possible side effects $(76,85)$. Gacyclidine, an NMDA receptor antagonist, has been evaluated in France in a phase-II double-blind, randomized evaluation of 280 patients with SCI (86). However, this study reveals no remarkable improvement in American Spinal Injury Association (ASIA) scores compared with placebo treatment. White matter glial loss is reduced and locomotor function can be improved by focal microinjections of NBQX, an AMPA receptor blocker, into the injured spinal cord areas after blunt injury (87). Unfortunately, this invasive form of receptor antagonism has not been developed into pharmacological therapies due to several side effects (87). Magnesium is an NMDA receptor antagonist that reduces excitotoxicity and inflammatory factors (88). However, cerebrospinal fluid levels are increased by the combination of magnesium and polyethene glycol (PEG) without large doses of magnesium (86). The enhancement of tissue sparing and the action of magnesium produces an improvement of functional motor recovery with PEG in the treatment of SCI in animal models (86). However, a phase I/II clinical trial for the combination of magnesium and PEG was ended in 2015, due to several difficulties in enrolling patients.

Ion channel antagonists. Calcium channel blockers display significant effects on reducing the pathological influx of calcium into cells via non-glutamate receptors (78). However, the potent physiological impacts of calcium blockers are regulated via their pharmacological activity on vascular smooth muscle, rather than inducing calcium flux across neuronal and glial cell membranes (78). In experimental SCI models, nimodipine (NDP) can improve spinal blood flow and rescue hypoperfusion (77). NDP administration can significantly improve neurological recovery following spinal cord trauma or ischemia (Table I) (89). NDP was first studied in France in a potential randomized clinical trial of 160 patients within $8 \mathrm{~h}$ of injury: Methylprednisolone (MPSS), NDP $0.15 \mathrm{mg} / \mathrm{kg} / \mathrm{h}$ for $2 \mathrm{~h}$, then $0.03 \mathrm{mg} / \mathrm{kg} / \mathrm{h}$ for 7 days; both MPSS and NDP or placebo (90-92). Studies demonstrate that blood flow and neurological recoveries are promoted by dopamine, adrenaline, NPD and dextran following SCI (77,93-95). It is difficult to prove any firm effects in neurological outcomes after 1 year of injury. The administration of calcium channel blockers in acute SCI raises concerns regarding the potential for systemic hypotension that, in the context of the injured spinal cord, could be harmful due to autoregulation (18). The administration of sodium channel blockers notably improves the neuroprotection of white matter and functional outcomes with microinjections of tetrodotoxin after blunt experimental SCI (96). Even though surgery is required, similar neuroprotective effects have been observed for the administration of riluzole, another sodium channel blocker, after a clip compaction injury to a rodent spinal cord (97). The US Food and Drug Administration has recently approved riluzole for the treatment of amyotrophic lateral sclerosis. Notably, riluzole has an important role in protecting against excitotoxic cell death by blocking the sodium channel in the injured neurons constraining the presynaptic toggle of glutamate (97). Neuronal loss and cavity size have been reduced in SCI animal models (98). A significant improvement of sensorimotor and results of electrophysiological were demonstrated in a previous study (66). A phase-I trial has been completed in which 36 patients $(50 \mathrm{mg}$ orally every $12 \mathrm{~h}$ for 14 days) participated (99). This study demonstrates a substantial increase in motor recovery following cervical injury at 3 months compared with matched registry control patients. Enhanced motor scores were not observed at 6 months follow-up. Regarding the neurological results, an improvement in ASIA motor score was demonstrated in patients with cervical SCI treated with riluzole compared with non-riluzole-treated patients. Although a transient increase in liver enzyme levels was found, a number of pharmacokinetics and toxicity effects have not been investigated (99). Nevertheless, the therapeutic application of riluzole has yet to be documented. Further studies should be carried out for its therapeutic use in patients with SCI. A phase-II/III multicenter randomized controlled trial of riluzole is currently underway by the AO Spine North America Research Network (100).

Blocking potassium channels may be a potential therapeutic target for the treatment of SCI. A patient with chronic SCI taking 4-aminopyridine (4-AP) demonstrated an increase of the axonal regeneration with mild levels of recovery (101). Similarly, an animal model of SCI supports the potential effects of 4-AP on blocking the fast potassium channels. 4-AP exhibits the most significant improvement in conduction in chronic SCI (102). Fampiridine is a fast potassium channel blocker, which has completed phase-II clinical trials and 


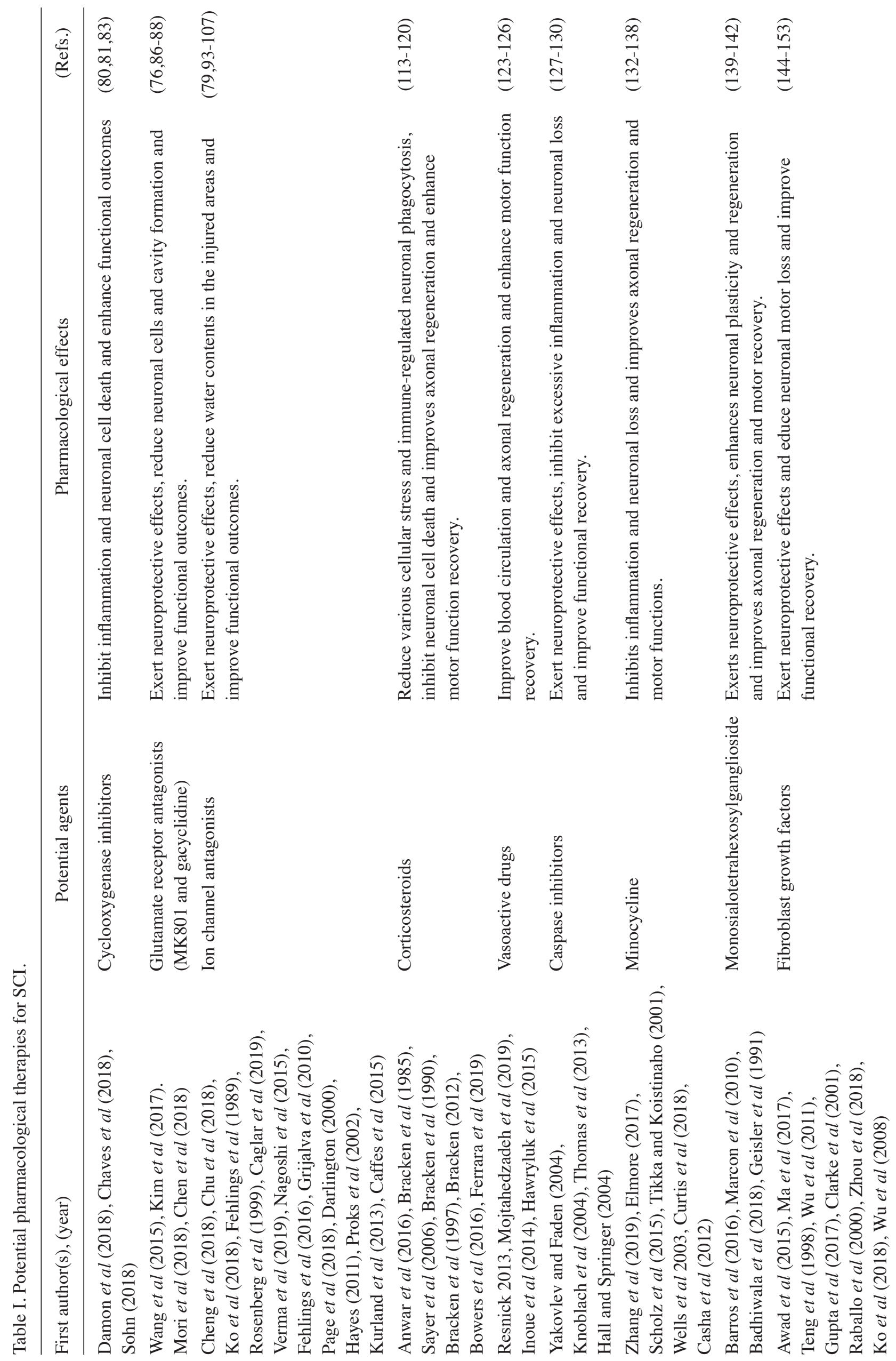




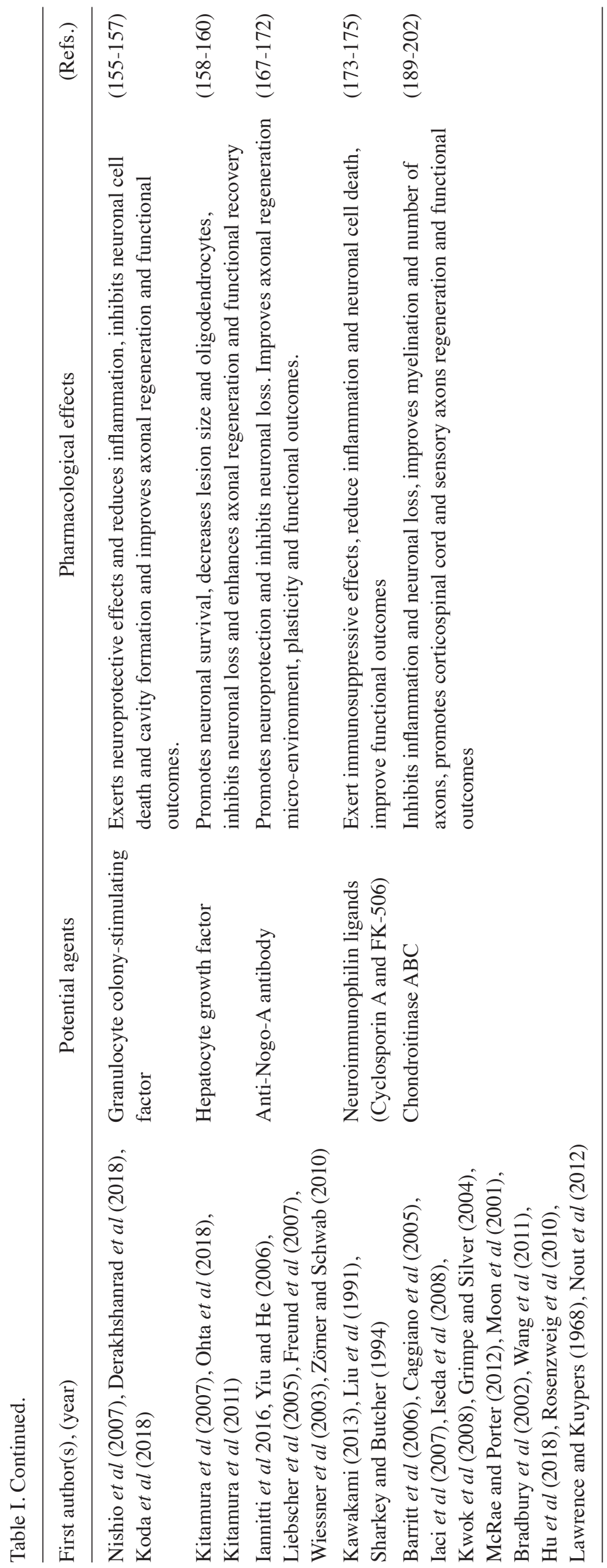




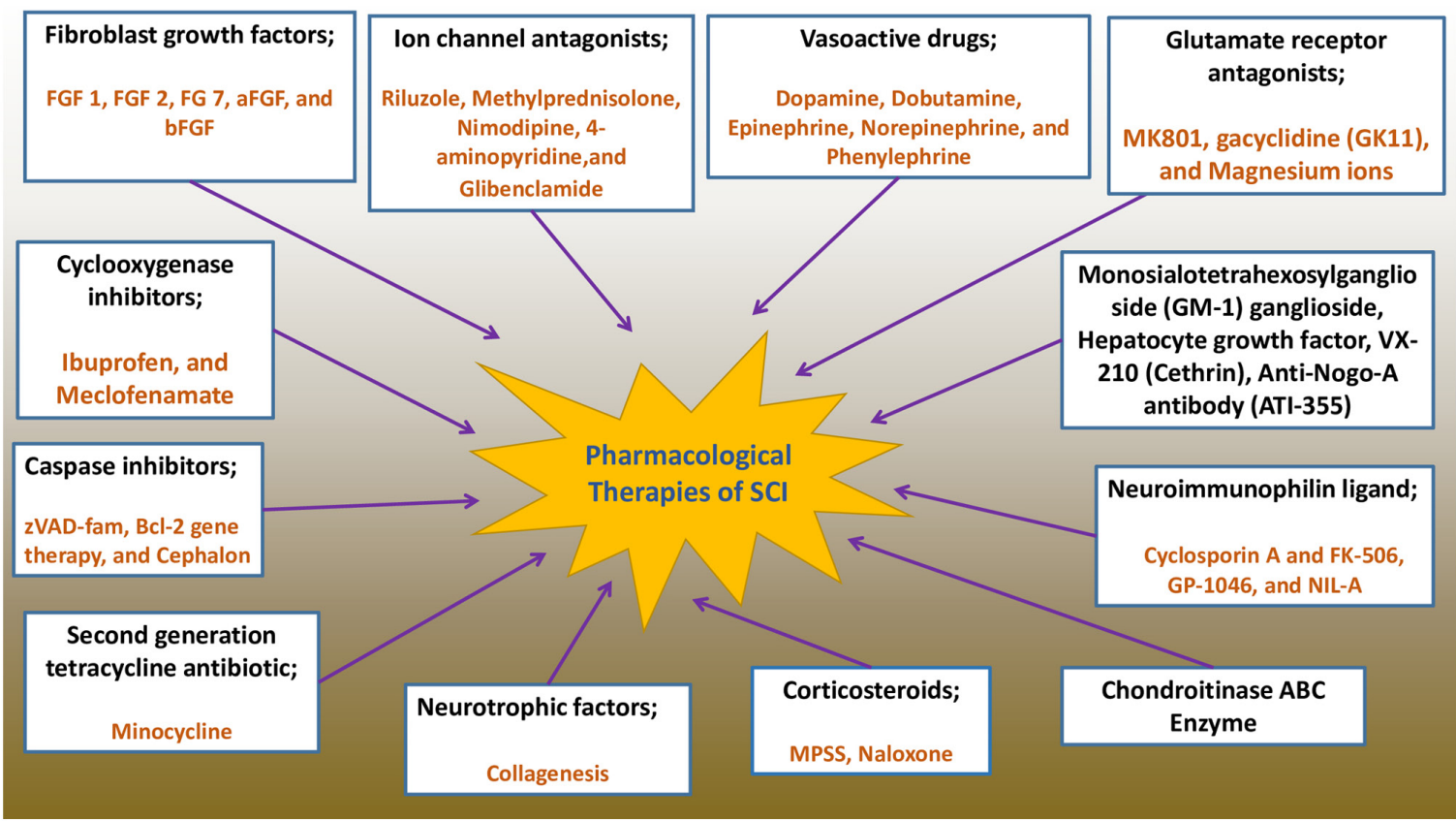

Figure 2. Different type of pharmacological drugs used for the treatment of SCI. SCI, spinal cord injury; FGF, fibroblast growth factor; a, acidic; b, basic.

is co-developed by Elan and Acorda Therapeutics (103). In some small clinical trials, chronic SCI patients with incomplete injury have demonstrated improved patient satisfaction, quality of life scores, sensory and motor scores, decreased spasm and increased amplitude following fampiridine administration $(103,104)$. In addition, this potent drug has good tolerance and few side effects (102). In another study, patients treated with 4-AP exhibit less impact on functional status (104). This beneficial mechanism demonstrates that potassium channel blockade enhances axonal transmission between demyelinating nodes, and enhances neuronal and neuromuscular transmission in the preserved axons (103). Thus, further investigations in greater detail are urgently required to explore the potential benefits of potassium channel blockers in improving axon conduction in patients with the chronic injury. If more axons are retained in the acute phase following SCI, the potential of this treatment may be more substantial.

Glibenclamide (GLC) is a sulfonylurea receptor 1-regulated, transient receptor potential cation channel subfamily $\mathrm{M}$ member 4 channel, $\mathrm{Ca}^{2+}$-activated, non-specific cation channel blocker that is commonly used to treat diabetes by increasing insulin release (105). It exhibits substantial neuroprotective effects in ischemic hemorrhagic stroke and traumatic brain injury models $(106,107)$. GLC reduces hemorrhagic necrosis, edema and inflammation in SCI $(108,109)$. In animal models, GLC reduces hemorrhage at $24 \mathrm{~h}$ after injury and minimized the lesion size at 1-6 weeks (110). GLC treatment significantly improves functional recovery following SCI within 6 weeks. In one animal study, the improvement of bilateral injury (33\% reduction in lesion size) was more limited compared with unilateral injury (57\% reduction in lesion size) at 6 weeks following GLC treatment (111). These findings illustrate that the severity of the damage may play significant roles in the functional recovery outcomes. In conclusion, GLC can be potentially useful in the treatment of SCI.
Corticosteroids. The National Acute Spinal Cord Injury Study (NASCIS) is a large randomized clinical trial of SCI, which has investigated the therapeutic role of corticosteroids (CSs) in SCI and produced high-quality data (112). CSs can significantly reduce various cellular stresses, including oxidative stress associated with hypoperfusion, calcium influx and excitotoxicity, and immune-regulated neuronal phagocytosis in the injured spinal cord (113). All NASCIS trials have yet to demonstrate benefits ascertained by primary outcome measures.

Numerous investigations reveal the potential effects of CSs. NASCIS-I published a paper in 1984, compared low-dose and high-dose MPSS (100 mg bolus and $100 \mathrm{mg}$ /day vs. 1,000 mg bolus and $1,000 \mathrm{mg} /$ day) following SCI (114). No significant differences in neurological improvement were observed in this study, but high-dose MPSS administration can increase several physical complications including gastrointestinal bleeding, sepsis, wound infection, pulmonary embolism and even mortality (115). Notably, a placebo was not provided in the NASCIS-I study, because CS was considered effective and to not apply them raised ethical concerns. NASCIS-II assessed high-dose MPSS within $24 \mathrm{~h}$ of SCI compared with naloxone, opioid antagonists and placebo $(115,116)$. A pre-planned subgroup analysis illustrated that the patients administered with MPSS within $8 \mathrm{~h}$ of injury could demonstrate substantially enhance motor function recovery. NASCIS-III assessed MPSS and tirilazad mesylate (21 aminosteroids with antioxidant effect) within $8 \mathrm{~h}$ after injury and is the first NASCIS study to use functional measurement results. CS $(30+5.4 \mathrm{mg} / \mathrm{kg})$ were compared at 24 and $48 \mathrm{~h}$ with tirilazad mesylate $(2.5 \mathrm{mg} / \mathrm{kg}$ every $6 \mathrm{~h}$ ) at $48 \mathrm{~h}$. Subgroup analysis demonstrated that patients who received MPSS bolus 3 to $8 \mathrm{~h}$ after injury and were infused within $48 \mathrm{~h}$ exhibit improved neurological functions within 1 year. Following this study, MPSS was recommended for $24 \mathrm{~h}$ in patients treated within $3 \mathrm{~h}$ of injury and $48 \mathrm{~h}$ in patients treated within 3-8 h of injury. The treatment of acute 
SCI with MPSS is still controversial. Recent guidelines give first-class evidence against the application of CSs in SCI (117).

A randomized controlled trial reported that MPSS administration within $8 \mathrm{~h}$ of injury is significantly effective in SCI (118). This study demonstrated the lack of other therapeutic strategies and MPSS is the only drug to be investigated in phase-III trials. Notably, a previous study also suggested that CS administration has limited efficacy and increases several physical complications, including septicemia and pneumonia (119). A study of 77 patients with SCI demonstrates that despite limited risk and efficacy, most patients prefer to take CS (120). By contrast, 59.4\% of the patients considered that the chance of neurological recovery was improved and that it was worth using CS. Only a few $(1.4 \%)$ hypothesized that it was inappropriate to use CS. These findings should be explored by health practitioners caring for the treatment of SCI patients. The upcoming AO Spine-guidelines for the management of acute SCI will reinstate the NASCIS-II dosing of MPSS administered within 3 to $8 \mathrm{~h}$ after injury to level-III treatment strategy (121).

Vasoactive drugs. Primary supportive care during acute SCI maintains spinal cord perfusion and oxygenation. Injuries above the T6 vertebra can cause sympathetic nerve damage and neurogenic shock. Liquid administration and vasoactive drugs are widely used in the treatment of SCI (122). Following volume resuscitation, vasoactive drugs can be used to increase blood pressure, aimed at improving spinal cord perfusion (123). Patients with acute SCI can limit tolerance for intravascular volume expansion in the context of impaired sympathetic outflow. Several pharmacological agents, including dopamine (1-10 $\mathrm{mg} / \mathrm{kg} / \mathrm{min})$, dobutamine $(5-15 \mathrm{mg} / \mathrm{kg} / \mathrm{min})$, epinephrine (1-8 $\mathrm{mg} / \mathrm{min})$, norepinephrine $(1-20 \mathrm{mg} / \mathrm{min})$ and phenylephrine (10-100 $\mathrm{mg} / \mathrm{min})$, can be considered (124). Norepinephrine and dopamine result in vasoconstriction and enhance cardiac activity. Inoue et al (125) found that dopamine is most commonly used as a vasoactive drug, followed by epinephrine, phenylephrine, norepinephrine and vasopressin. The study suggested that both dopamine and phenylephrine administration can increase cardiovascular complications. Patients with a mean arterial pressure $>85 \mathrm{~mm} \mathrm{Hg}$ enhance their ASIA-score recovery (126). This study also suggests that this important therapeutic strategy might be effective soon after injury.

Caspase inhibitors. Following traumatic SCI, the preservation of axons can significantly enhance their overall function, even in a small number. Studies have demonstrated that the activity of caspase- 1 and caspase- 3 in neurons and non-neuronal cells increases following SCI $(127,128)$. Treatment using a broad-spectrum caspase inhibitor, such as Z-VAD-FMK, can reduce the area of post-traumatic injury and neurological deficit, as the therapeutic window of Z-VAD-FMK is extended by $9 \mathrm{~h}$ following transient (30 min) cerebral ischemia (128). It can be inferred that this treatment regimen may have a neuroprotective effect and prolong the therapeutic window of the drug following SCI. Bcl-2 gene therapy and cephalon, a protease/calpain inhibitor, have completed pre-clinical studies and appear beneficial to patients with SCI $(129,130)$. However, targeting long-term delayed caspase activation in oligodendrocytes may also be a potential treatment, as it may save the degenerated white matter and significantly improve patient prognosis.

Minocycline (MIN). MIN is a tetracycline antibiotic and previous studies have shown that it exhibits significant neuroprotective activities in Huntington's disease and multiple sclerosis $(131,132)$. MIN can significantly impede the activation of IL-1 $\beta$, TNF- $\alpha$, COX-2 and MMPs following SCI (132). In addition, MIN administration can substantially hinder the expression of caspase-1 and caspase-3 levels following SCI (133). MIN also inhibits inducible nitric oxide synthase, leading to microglial activation following SCI (134). MIN protects neurons from glutamate excitotoxicity at the injured spinal cord tissue area (135). Thus, MIN is a useful drug, since it targets multiple processes involved in mediating cell death and prevents the progression of secondary injury following SCI. A previous study demonstrated that MIN can enhance significant long-term functional outcomes in a mouse model (136). MIN-treated mice showed continual and substantial improvements over a 4-week recovery period. MIN administration could significantly enhance the Basso, Beattie, and Bresnahan scores at 20 days post-injury. In the injured mouse model of SCI, consistent weight support and considerable plantar stepping were found, while some mice indicated evidence of forelimb-hindlimb coordination. MIN could also improve neurological and histological outcomes, impede neuronal and oligodendroglial apoptosis, minimize microglial activation and inhibit inflammation in animal SCI models (131). MIN significantly reduces the lesion size and promotes tissue sparing following acute SCI (131). Patients with acute incomplete cervical SCI can benefit from early MIN administration (128). These findings were supported by a phase-II clinical trial where a 14-point ASIA motor score recovery was achieved compared with the placebo (137). The development of a phase-III trial entitled 'Minocycline in Acute Spinal Cord Injury' has been driven by these initial outcomes and was evaluated for 7 days (compared with placebo) using an intravenous administration of MIN (138).

Monosialotetrahexosylganglioside (GM-1). The glycosphingolipid GM-1, stimulates tyrosine kinase receptors, which increases neuronal plasticity and regeneration (139). Successful tissue sparing has been developed to study neuroprotection in an animal model of SCI $(42,140)$. A successfully completed phase-II trial shows enhanced 1-year ASIA motor scores after daily administration of GM-1 for 18-32 days post-injury (141). Additionally, a landmark trial indicates a substantial improvement in ASIA motor score and Frankel grade following GM-1 administration in 37 patients with SCI (142); lower limb function was markedly improved at $48 \mathrm{~h}$ following treatment with GM-1. Thus, this study demonstrated that GM-1 serves an important role in the repair of neurons. Although these initial findings led to a large-scale phase-III trial involving $>750$ patients in 28 centers, the major findings of the study failed to meet the primary outcomes (2-point improvement in the improved Benz walking scale) (137). The two groups showed a substantial improvement in bowel/bladder recovery and sacral function, as well as a remarkable improvement in functional independence scores and an enhanced Barthel index. Intensive physical therapy was also combined with pharmacological 
therapy to improve the prognosis of patients in the study. A valid criticism of this study is the delayed therapeutic effects of GM-1 treatment, as most of the patients received MPSS for the first time in their clinical treatment (137). Meta-analyses to evaluate the potential therapeutic benefits of GM-1 in the treatment of SCI failed to support its extensive use $(136,142)$.

Fibroblast growth factors (FGFs). FGFs are heparin-binding proteins that have significant neuroprotective activity against excitotoxicity and in impeding the generation of oxygen free radicals (143). FGFs determine the fate of neuronal cells, including migration and differentiation $(144,145)$. The administration of FGFs can reduce neuronal motor loss and improve respiratory deficits $(146,147)$. A phase-I/II trial of an FGF analog is successfully completed (148). Several growth factors possess neuroprotective effects and can enhance functional recovery in SCI (144). FGF1 administration can improve the survival and growth of various neuronal cell types, including neocortical, hippocampal, cerebellar, dopaminergic, isolated sensory neuronal and spinal cord cells $(145,149)$. In addition, basic FGFs and/or keratinocyte growth factor possess significant neuroprotective effects in SCI (150). Although preliminary studies of FGFs in animals are obligatory and essential, reviews on SCI should focus more on human trials (151). Ko et al (152) were the first to demonstrate a clinical trial involving a patient suffering from chronic SCI, who was treated with four survival nerve grafts coupled with fibrin glue containing acidic FGF (aFGF). The authors suggest that patients with acute SCI can significantly enhance functional recovery from their wheelchair-bound status and independently ambulate using a walker, 2.5 years after surgery (152). The authors also report that ASIA motor and sensory scores are significantly enhanced in postoperative functional status patients compared with presurgical patients. Wu et al (153) conducted a clinical trial on nine patients with cervical SCI, who received direct spinal cord implantation of fibrin glue containing aFGF for $>6$ months. The 6 -month postoperative follow-up indicated a marked enhancement in the ASIA motor and sensory scale scores of patients. After 3 years, the authors published an open-labeled, prospective, uncontrolled human clinical trial involving 60 patients with SCI (comprising 30 cervical and 30 thoracolumbar SCIs) and significant improvement in ASIA motor and sensory scale scores was observed in these patients at 24 months, following FGF treatment (147). Detailed studies are required to explore the potential therapeutic effects and long-term outcomes.

Granulocyte colony-stimulating factor $(G-C S F)$. G-CSF is a cytokine glycoprotein located in numerous tissues in the body. Several studies report that G-CSF can significantly promote the proliferation, survival and mobilization of neuronal cells (147-149). Increasing evidence suggests that G-CSF can enhance neurogenesis, reduce apoptotic-mediated neuronal death, and reduce TNF- $\alpha$ and IL- $1 \beta$ expression levels at the injured spinal cord area (154-156). White matter sparing and improved hind-limb function are the positive effects associated with this therapy (154). Non-randomized phase-I/IIa trials have indicated ASIA grade improvement, without any adverse effects, associated with G-CSF therapy (155-157). However, additional randomized controlled trials are needed to establish the potential therapeutic benefits of G-CSF in SCI. Recently, a phase-III clinical trial of G-CSF in Japan has been completed, but the results are pending.

Hepatocyte growth factor (HGF). HGF, found in mesenchymal cells, induces cell growth and motility (150). HGF administration can enhance neuronal survival, decrease lesion size and reduce the production of oligodendrocytes in rodent models (158). Furthermore, HGF treatment markedly improved hand dexterity in a primate model of cervical SCI $(159,160)$. A recent study showed that the specific receptor, c-Met, of HGF increases sharply while the upregulation of endogenous HGF is relatively weaker in a rat model with acute SCI (161). By injecting an HGF expression vector into the spinal cord of rats, the survival rate, angiogenesis and axon regeneration of neurons and oligodendrocytes following SCI show significant improvement. The injured area shows reduction and functionality is restored (161). The exogenous administration of HGF in acute SCI can reduce the activation of astrocytes, reduce the formation of glial scars, exert anti-inflammatory effects and reduce the infiltration of leukocytes (161). Recombinant human HGF (intrathecal rhHGF) injection improves the neurological functions following cervical contusion in non-human primates (160). Based on these findings, a phase-I/II clinical trial of intrathecal rhHGF conducted between June 2014 and May 2018 involving patients with acute cervical SCI revealed that the patients had a Frankel score of A/B1/B2 $72 \mathrm{~h}$ after the initial injury (160).

$V X-210$ (Cethrin). The $\rho$-signaling pathway is detrimental to axonal regeneration and neurite growth (162). In a rodent model of SCI, $\rho$-mediated inhibition of axonal growth enhances neuronal regeneration and recovers the motor function induced by $\mathrm{C} 3$ transferase (Cethrin), a toxin produced by Clostridium botulinum (163). During decompressive surgery in the acute phase, Cethrin is injected into the dura mater due to its high permeability at regions of the injured spinal cord tissue.A phase-I/IIa multicenter trial of VX-210 in patients with cervical or thoracic SCI showed a significant improvement of $1.8 \pm 5.1$ points in the ASIA motor score for thoracic injury and $18.6 \pm 19.3$ points for cervical injury (164). In addition, 31 and $6 \%$ of patients showed an improvement in ASIA C or D classification of cervical or thoracic injury, respectively. The largest and most significant improvement was observed at 12 months in the treatment of patients with cervical injury using $3 \mathrm{mg}$ Cethrin (27.3 points) (165). It is worth noting that RhoA impedance and subsequent functional enhancement are also reported when non-steroidal anti-inflammatory drugs, such as ibuprofen, are used for therapy, indicating that targeting COX may be a potential therapeutic option in treating SCI (166).

Anti-Nogo-A antibody (ATI-355). ATI-355 is one type of monoclonal antibody against Nogo-A and can significantly inhibit the adult CNS myelin component (167). It can markedly impede neurite growth and plasticity in adult CNS, enhance axon growth and regeneration, and stabilize neuronal circuits (168). Blocking myelin protein Nogo-A function or its signaling pathway is an emerging strategy to suppress the release of neurite growth inhibitory factor of the adult central CNS and improve the axonal regeneration micro-environment 
and plasticity following SCI (168). Anti-Nogo-A antibody treatment following SCI can significantly enhance axonal regeneration at the injured tissue area, and improve compensatory sprouting and functional recovery $(165,169)$. Similar therapeutic effects are found in a SCI macaque monkey model (170). A study evaluated the potential therapeutic effects of acute, as well as 1 or 2 weeks delayed intrathecal anti-Nogo-A antibody infusions, on corticospinal tract (CST) axon regeneration and motor function recovery following thoracic SCI in experimental rat models (165). Lesioned CST fibers regenerated over several $\mathrm{mm}$ following acute or 1 week-delayed treatments, but not when the antibody treatment was started following a delay of 2 weeks. Notably, Anti-Nogo-A antibodies administration can significantly neutralize inhibitory effects on neurite growth of purified or recombinant Nogo-A, oligodendrocytes and CNS myelin in vitro (171). A phase-I human clinical trial with humanized anti-Nogo antibody in patients with SCI has been completed in Europe and the United States (172).

Neuroimmunophilin ligands. Cyclosporin A and FK-506 are neuroimmunophilin ligands, which exhibit neuroprotective activity in experimental models, including those of ischemia, trauma and neurogenerative CNS disorders (173-176). These drugs are commonly used as immunosuppressants and are capable of crossing the BBB $(173,176)$. GP-1046 is a novel neuroimunophilin ligand, which was initially synthesized by Gold et al (177) but was then replaced with NIL-A, which binds with FK506 binding protein (FKBP)-12 in neuronal tissues. NIL-A is currently in phase-II clinical trials for the treatment of SCI (177). Vertex Pharmaceuticals has conducted a preclinical trial on the neurophilin ligand, V10367, which can significantly bind to the FK-506 binding protein, FKBP-12 (178). Results and opinions on the clinical use of neuroimmunophilin ligands to enhance neuronal outgrowth are conflicting; therefore, additional studies are needed for further validation (178).

Neurotrophic factors. There are different ways to administer neurotrophic factors to the injured spinal cord. Direct injection, continuous injection and growth factor-saturated gel are typically used, although these methods are not that efficient (179). However, collagenases are currently used, which involve collagen-based drug therapy as an improved method for the effective delivery of neurotrophic factors (180). An alternative approach that can overcome these shortcomings is ex vivo therapy. This involves removing cells (including Schwann cells and fibroblasts) from the host, genetically modifying them in vitro to synthesize specific neurotrophic factors, expanding the cells in culture and re-transplanting them into the host $(180,181)$. The technique provides a significant long-term, localized, high-dose growth factor upon delivery. Gene therapies are currently being pursued by Selective Genetics, Cell Genesys, Biovex, Oxford Biomedica and Amsterdam Molecular Therapeutics (182). Ex vivo therapies are not very effective in promoting distal axonal growth after the initial axonal growth, although only a few studies have been conducted so far $(183,184)$. The adverse effects, complications and potential risks of gene therapy must be carefully considered before implementation. However, Proneuron Biotechnologies provides autotherapy of the larger arteries, where the cells of the patient are removed, activated and returned to stimulate nerve regeneration (185). Some preclinical studies show that macrophages or cytokines can be injected to promote inflammatory responses and functional outcomes $(186,187)$. Efforts should be made to determine the potentially destructive role of macrophages in removing cell debris, promoting tissue blood flow, reconstruction, restoring phagocytic capacity and inducing cellular proliferation around the injured spinal cord by releasing factors to stimulate scar formation (30). This technology is currently in phase-I clinical trials.

Chondroitinase $A B C$ (ChABC) enzyme. Following SCI, axons of the CNS in adult mammals cannot regenerate correctly, resulting in permanent paralysis. Glial reaction occurs at the injured area, forming a glial scar (188). The glial response leads to the recruitment of microglia, oligodendrocyte precursors, meningeal cells, astrocytes and stem cells, as well as oligodendrocytes and myelin fragments $(189,190)$. The majority of these cells release molecules and inhibit axon regeneration, which leads to regeneration failure $(177,178)$. The glial scar also contains chondroitin sulfate proteoglycan (CSPG), a recovery inhibitor (191). However, the natural bacterial enzyme ChABC can degrade the inhibitory carbohydrate side chains on CSPG. Indeed, ChABC administration following SCI can promote corticospinal cord and sensory axon regeneration, and enhance functional outcomes (192). These growth-promoting effects of ChABC are due to the elimination of perineuronal nets, increased germination of spare axons and the formation of new synaptic connections under the injured sites (180). ChABC may enhance axonal regeneration in the severed axon on the bridge (192). The potential therapeutic effects of ChABC administration have been identified in rodent models of SCI, nigrostriatal injury and stroke, and cats with SCI (193-195). In a study in male Wistar rats, using a combination of low-level laser therapy (LLLT) as an anti-inflammatory agent and ChABC as a CSPG digesting factor after inducing SCI by clip compression, the combination of LLLT and ChABC produced beneficial effects in the form of reductions in cavity size, increased myelination and number of axons around the cavity, and reduced glycogen synthase kinase-3 $\beta$, CSPG and aquaporin 4 expression compared with LLLT and ChABC alone, resulting in greater functional recovery in the combination group (196). ChABC treatment in rats can restore postsynaptic activity under injury, which is significant for the electrical stimulation of corticospinal neurons and enhances the functional recovery of motor and proprioceptive behavior (197).

After 4 weeks of acute SCI, ChABC combined with rehabilitation therapy can also promote functional recovery (198). In a recent study on dogs with severe chronic SCI, intracerebral injection of ChABC demonstrates impressive results (199) and the authors suggest that human trials be commenced. The effect of ChABC has been evaluated in rhesus monkeys that had undergone C7-spinal cord hemisection $(200,201)$. At 4 weeks after hemisection, multiple-intraparenchymal $\mathrm{ChABC}$ injections were administered below the lesion area, targeting spinal cord circuits, which regulate hand functions $(202,203)$. Compared with the vehicle injection control group, the hand function of the monkeys treated with $\mathrm{ChABC}$ 


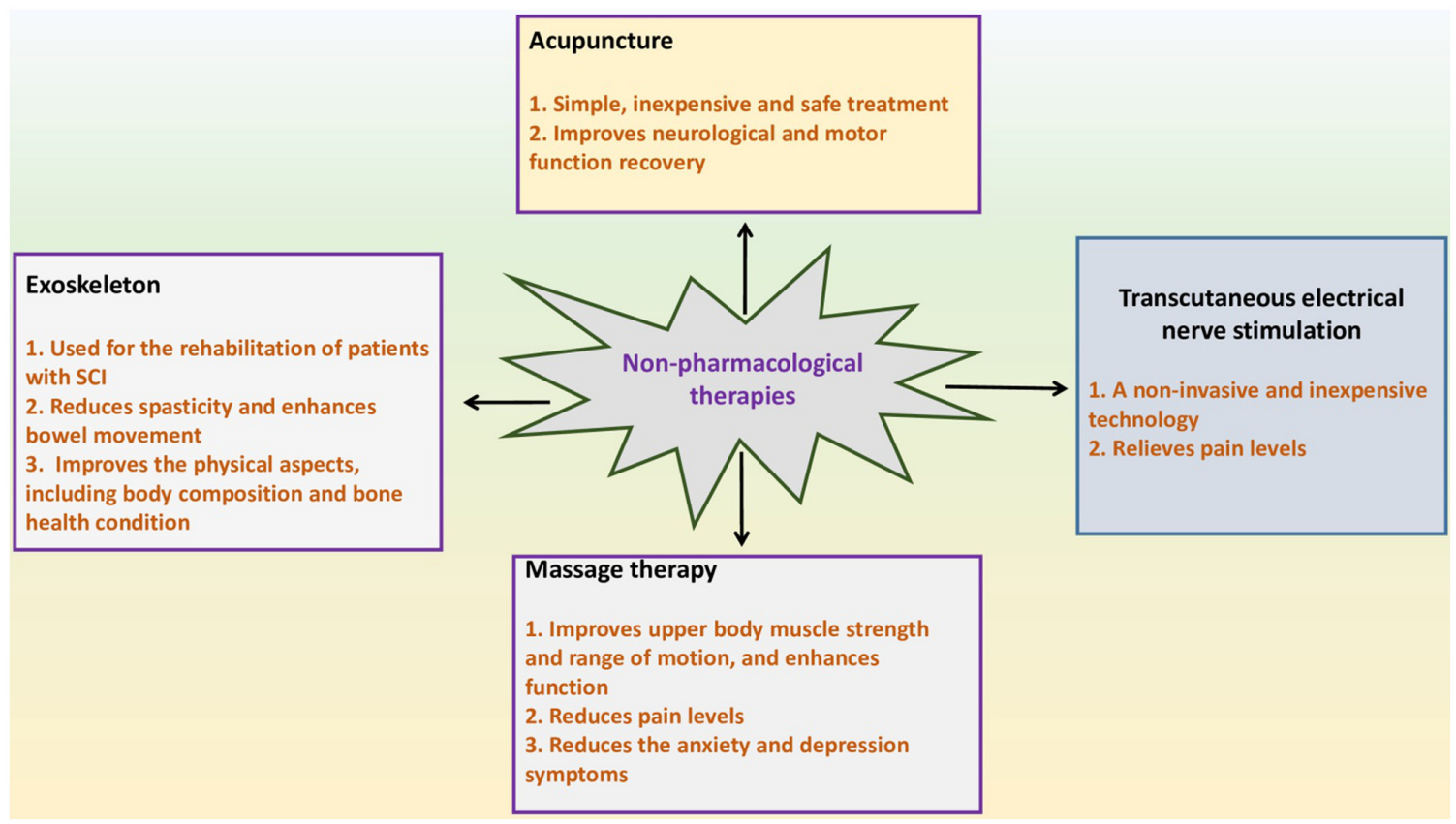

Figure 3. Non-pharmacological therapies for the treatment of SCI. SCI, spinal cord injury.

was significantly improved. In addition, ChABC can substantially increase the regeneration of corticospinal axons and synapses formed by corticospinal terminals in the gray matter caudal to the lesion (202). No harmful effects were identified. This method may be helpful for the clinical treatment of SCI. Although no human trial has been carried out thus far, the results of animal studies are promising and point to the potential benefits of ChABC in SCI treatment.

\section{Non-pharmacological therapies for SCI (Fig. 3)}

Acupuncture (ACP). Previous studies show that recovery of motor and sensory function following SCI is the most crucial and challenging step in rehabilitation (194,195). In addition, axonal regeneration and functional recovery following SCI are limited and challenging, especially in patients with SCI, whose paralysis duration can last a year or more. ACP is a simple, inexpensive and safe treatment, which is widely used for improving the recovery of motor and sensory function in patients with SCI (204). ACP can not only improve motor function but also promote nerve recovery $(205,206)$. Electroacupuncture can inhibit the proliferation of astrocytes, downregulate the levels of platelet-derived growth factor and enhance motor neurons in the hind limbs of rats by inhibiting neuronal apoptosis and regulating the expression of related genes $(207,208)$. ACP can significantly enhance the recovery of the function of motor neurons in the anterior horn of rats with SCI by augmenting the activity of acetylcholinesterase, which can upregulate the activity of neurotrophic factor mRNA (208). A study investigating the benefits of ACP therapy in neurological recovery following SCI reported that ACP therapy can substantially improve neurological and motor function recovery (204). The study also indicated that studies involving acute cases of SCI and those using different ACP treatments can achieve more significant therapeutic results in treating SCI.
Massage therapy (MT). Another study evaluated the beneficial effects of massage and exercise therapy on C5-C7 SCI (209).MT can improve upper body muscle strength and range of motion, and enhance function (209). Previous studies suggested that MT increases the range of activity and reduces the level of pain in patients with lower back pain, such as dancers $(202,210)$. MT also reduces stiffness, pain and fatigue in patients with fibromyalgia $(209,211)$. Furthermore, MT can reduce the symptoms of anxiety and depression in patients with SCI (212). Notably, MT reduces self-reported anxiety and depression, decreases the levels of stress hormones (cortisol and noradrenaline) and increases serotonin levels in adults (210). Exercise programs can enhance muscle strength, the range of motion and function and reduce depression and anxiety in patients with SCI (213). Patients with SCI who receive MT twice a week for 5 weeks demonstrate a significant enhancement in muscle strength, as well as in fine motor (wrist) range, compared with those in an exercise group (210). It was previous reported that an improvement in muscle strength and range of motion could significantly reduce depression and anxiety in patients with SCI (201). A study that evaluated the psychological aspects of patients show that MT can significantly mitigate depression and anxiety (209). Depression is common in patients with SCI and negatively affects their quality of life (214). Therefore, these findings indicate that patients with SCI may benefit from MT. A detailed investigation is required to evaluate MT for other SCI issues, such as spasticity and pain. Additionally, further studies are required to assess the potential effect of MT in the lower extremities of patients with SCI, especially those with affected C5-C7 vertebrae, in improving circulation and reducing muscle atrophy.

Transcutaneous electrical nerve stimulation (TENS). Electrotherapy is a non-invasive and inexpensive technique. Thus, a number of physical therapists recommend it to treat patients with SCI (215). TENS is generally used to relieve pain 
during electrotherapy (211). Increasing evidence reveals that TENS is a safe treatment intervention with fewer side effects for most patients compared with other existing therapies (204). Several clinical investigations report that TENS has clear benefits in the management of SCI; however, there are controversies regarding treatment conditions and the appropriate parameters that should be adhered to during therapy using TENS $(216,217)$. Some randomized controlled trials have explored the pain relief that can potentially be achieved using TENS and investigated its potential benefits in patients with SCI $(218,219)$. A randomized clinical trial reported that TENS could significantly relieve pain in patients with SCI (220). Based on the visual analog scale, present pain intensity- $\mathrm{T}$, pain rating index-S, pain rating index-A, present pain intensity and number of words chosen outcomes, a study indicated that 12 weeks of TENS could relieve pain in patients with SCI (220). Notably, the pain levels were significantly reduced in the TENS-treated patients with SCI $(219,221)$. These results also indicate that TENS induces substantial effects in patients with SCI. A total of 33 patients with SCI were enrolled and were randomly assigned to the TENS and control groups (222). Patients in the TENS groups received $30 \mathrm{~min}$ of TENS, while those in the control group were assigned $30 \mathrm{~min}$ of sham TENS, once a day for 10 days. Hagen and Rekand (223) demonstrated that TENS could efficaciously relieve the pain of patients with SCI. In conclusion, TENS can be a useful approach to treat patients with SCI.

Electric exoskeleton (EXO). EXO using robotic suits is widely used for the rehabilitation of patients with SCI (224). EXO provides an alternative opportunity for patients with SCI to experience standing and walking at a low metabolic cost (224). EXO-supported walking can considerably reduce spasticity and enhance bowel movement (225). A frequency of 2-3 times or more per week for 1-2 $\mathrm{h}$ can be beneficial to the rehabilitation of patients with SCI (224). Using EXO-supported walking to enhance physical activity level may be attractive for patients with SCI (224). Before the development of EXO, mobility options beyond a wheelchair were few for the majority of patients with SCI lacking leg movement (226). Robotic EXOs have become increasingly popular, and it is now possible to use them for personal purposes in families and communities (227). However, it is required for users to set realistic expectations. Robotic EXOs may allow individuals with SCI with diverse levels of injury to safely and functionally walk for personal mobility or exercise (226). In addition to the potential cardiovascular benefits, physical activities and proper standing may minimize the risk of contracture, osteoporosis, cramps, pressure sores and edema in patients with SCI, especially when used early after injury (228). There is evidence that the use of EXOs affects other health aspects (229). Karelis et al (230) reported that after 6 weeks of EXO training the BMD of the tibia increased by $14.5 \%$, which may have clinical significance, and the BMD of subcutaneous and muscular adipose tissue decreased by $5 \%$. EXO can significantly improve the physical aspects, including body composition and bone health condition (231). Similar to the way the amount of physical labor depends on individual factors, individual factors may also affect the degree of influence of exoskeleton on bone health (232). The effects on bone health can also be affected by different factors. For example, individuals who use EXO without the physical support of others may experience a significant effect on bone health compared with those who require physical support, because the ground reaction force of walking with the help of SCI exoskeletons is similar to healthy walking (233).

\section{Conclusions}

The pathophysiological processes following SCI are highly complex and the extent of our knowledge concerning these processes is limited. This is evident from the slow advancement of currently available neuroprotective methods compared with rapid trauma revitalization and other clinical interventions. Emerging studies continue to be added to the existing literature, comprising studies on inflammation, dysregulation, lipid peroxidation and apoptosis, which may be considered while developing suitable pharmacological therapies. Although drugs such as methylprednisolone, GM-1ganglioside and sodium channel blockers have undergone several clinical trials, other pharmacological agents and therapies have been reported to be efficacious in animal models of SCI. Additionally, some drugs show potential as candidates that can be further pursued as viable treatment options in the management of SCIs. Thus, this review considered and discussed various factors that are involved in the etiology, detection and management of SCIs, with a focus on the availability and use of current pharmacological and non-pharmacological therapies for this debilitating condition.

\section{Acknowledgements}

Not applicable.

\section{Funding}

The present study was partly supported by research grants from the National Natural Science Funding of China (grant nos. 81801233 and 81870842) and the Zhejiang Provincial Natural Science Foundation of China (grant no. LQ18H090011).

\section{Availability of data and materials}

Not applicable.

\section{Authors' contributions}

YZ and AAM wrote the paper. YY, QL, JX and SY participated in literature collection and producing the figures. $\mathrm{CW}$ participated in literature collection and edited the manuscript. YW and JW conceived the study and wrote the manuscript. All authors reviewed and approved the final manuscript.

\section{Ethics approval and consent to participate}

Not applicable.

\section{Patient consent for publication}

Not applicable. 


\section{Competing interests}

The authors declare that they have no competing interests.

\section{References}

1. Hamid R, Averbeck MA, Chiang H, Garcia A, Al Mousa RT Oh SJ, Patel A, Plata M and Del Popolo G: Epidemiology and pathophysiology of neurogenic bladder after spinal cord injury. World J Urol 36: 1517-1527, 2018.

2. Hu HZ, Granger N and Jeffery ND: Pathophysiology, clinical importance, and management of neurogenic lower urinary tract dysfunction caused by suprasacral spinal cord injury. J Vet Intern Med 30: 1575-1588, 2016

3. Elliott CS, Dallas KB, Zlatev D, Comiter CV, Crew J and Shem K: Volitional voiding of the bladder after spinal cord injury: Validation of bilateral lower extremity motor Function as a key predictor. J Urol 200: 154-160, 2018.

4. Sharma HS: Early microvascular reactions and blood-spinal cord barrier disruption are instrumental in pathophysiology of spinal cord injury and repair: Novel therapeutic strategies including nanowired drug delivery to enhance neuroprotection. J Neural Transm (Vienna) 118: 155-176, 2011.

5. Tator $\mathrm{CH}$ : Experimental and clinical studies of the pathophysiology and management of acute spinal cord injury. J Spinal Cord Med 19: 206-214, 1996

6. Hulsebosch CE: Recent advances in pathophysiology and treatment of spinal cord injury. Adv Physiol Educ 26: 238-255, 2002.

7. Tator $\mathrm{CH}$ and Deecke L: Studies of the treatment and pathophysiology of acute spinal cord injury in primates. Paraplegia 10: 344-345, 1973.

8. Xiong Y and Hall ED: Pharmacological evidence for a role of peroxynitrite in the pathophysiology of spinal cord injury. Exp Neurol 216: 105-114, 2009.

9. Wasner G, Naleschinski D and Baron R: A role for peripheral afferents in the pathophysiology and treatment of at-level neuropathic pain in spinal cord injury? A case report. Pain 131: 219-225, 2007

10. Vaidyanathan S, Soni BM, Sett P, Watt JW, Oo T and Bingley J: Pathophysiology of autonomic dysreflexia: Long-term treatment with terazosin in adult and paediatric spinal cord injury patients manifesting recurrent dysreflexic episodes. Spinal Cord 36 761-770, 1998

11. Austin JW, Afshar M and Fehlings MG: The relationship between localized subarachnoid inflammation and parenchymal pathophysiology after spinal cord injury. J Neurotrauma 29: 1838-1849, 2012.

12. Yezierski RP: Pain following spinal cord injury: Pathophysiology and central mechanisms. Prog Brain Res 129: 429-449, 2000.

13. Nickel M and Gu C: Regulation of central nervous system myelination in higher brain functions. Neural Plast 2018: 6436453, 2018

14. Fehlings MG and Agrawal S: Role of sodium in the pathophysiology of secondary spinal cord injury. Spine (Phila Pa 1976) 20 $2187-2191,1995$

15. Schwartz G and Fehlings MG: Secondary injury mechanisms of spinal cord trauma: A novel therapeutic approach for the management of secondary pathophysiology with the sodium channel blocker riluzole. Prog Brain Res 137: 177-190, 2002.

16. Sharma HS, Patnaik R, Sharma A, Sjoquist PO and Lafuente JV Silicon dioxide nanoparticles $(\mathrm{SiO} 2,40-50 \mathrm{~nm})$ exacerbate pathophysiology of traumatic spinal cord injury and deteriorate functional outcome in the rat. An experimental study using pharmacological and morphological approaches. J Nanosci Nanotechnol 9: 4970-4980, 2009.

17. Valles M and Mearin F: Pathophysiology of bowel dysfunction in patients with motor incomplete spinal cord injury: Comparison with patients with motor complete spinal cord injury. Dis Colon Rectum 52: 1589-1597, 2009.

18. Agrawal SK, Nashmi R and Fehlings MG: Role of L- and N-type calcium channels in the pathophysiology of traumatic spinal cord white matter injury. Neuroscience 99: 179-188, 2000.

19. Furlan JC and Fehlings MG: Cardiovascular complications after acute spinal cord injury: Pathophysiology, diagnosis, and management. Neurosurg Focus 25: E13, 2008.

20. Hayta E and Elden H: Acute spinal cord injury: A review of pathophysiology and potential of non-steroidal anti-inflammatory drugs for pharmacological intervention. J Chem Neuroanat 87: $25-31,2018$.
21. Hall ED: Pathophysiology of spinal cord injury. Current and future therapies. Minerva Anestesiol 55: 63-66, 1989.

22. Segal JL: Immunoactivation and altered intercellular communication mediate the pathophysiology of spinal cord injury. Pharmacotherapy 25: 145-156, 2005.

23. Delamarter RB, Sherman J and Carr JB: Pathophysiology of spinal cord injury. Recovery after immediate and delayed decompression. J Bone Joint Surg Am 77: 1042-1049, 1995.

24. Santos-Nogueira E, López-Serrano C, Hernandez J, Lago N, Astudillo AM, Balsinde J, Estivill-Torrús G, de Fonseca FR, Chun J and López-Vales R: Activation of Lysophosphatidic acid receptor type 1 contributes to pathophysiology of spinal cord injury. J Neurosci 35: 10224-10235, 2015.

25. Sharma HS, Badgaiyan RD, Alm P, Mohanty S and Wiklund L: Neuroprotective effects of nitric oxide synthase inhibitors in spinal cord injury-induced pathophysiology and motor functions: An experimental study in the rat. Ann N Y Acad Sci 1053: 422-434, 2005

26. Karimi-Abdolrezaee S, Eftekharpour E and Fehlings MG: Temporal and spatial patterns of Kv1.1 and Kv1.2 protein and gene expression in spinal cord white matter after acute and chronic spinal cord injury in rats: Implications for axonal pathophysiology after neurotrauma. Eur J Neurosci 19: 577-589, 2004.

27. Tator $\mathrm{CH}$ : Acute spinal cord injury: A review of recent studies of treatment and pathophysiology. Can Med Assoc J 107: 143-145, 1972.

28. Sharma HS, Muresanu DF, Sharma A, Patnaik R and Lafuente JV: Chapter 9-nanoparticles influence pathophysiology of spinal cord injury and repair. Prog Brain Res 180: 154-180, 2009.

29. Neal JM, Kopp SL, Pasternak JJ, Lanier WL and Rathmell JP: Anatomy and pathophysiology of spinal cord injury associated with regional anesthesia and pain medicine: 2015 update. Reg Anesth Pain Med 40: 506-525, 2015.

30. Wang X, Cao K, Sun X, Chen Y, Duan Z, Sun L, Guo L, Bai P, Sun D, Fan J, et al: Macrophages in spinal cord injury: Phenotypic and functional change from exposure to myelin debris. Glia 63: 635-651, 2015

31. Eldahan KC and Rabchevsky AG: Autonomic dysreflexia after spinal cord injury: Systemic pathophysiology and methods of management. Auton Neurosci 209: 59-70, 2018.

32. Sharma HS: Neurotrophic factors in combination: A possible new therapeutic strategy to influence pathophysiology of spinal cord injury and repair mechanisms. Curr Pharm Des 13: 1841-1874, 2007

33. Siddiqui TA, Lively S and Schlichter LC: Complex molecular and functional outcomes of single versus sequential cytokine stimulation of rat microglia. J Neuroinflammation 13: 66, 2016.

34. Zhou LH, Ouyang L, Lin SZ, Chen S, Liu Y, Zhou W and Wang X: Protective role of $\beta$-carotene against oxidative stress and neuroinflammation in a rat model of spinal cord injury. Int Immunopharmacol 61: 92-99, 2018.

35. Yao X, Zhang Y, Hao J, Duan HQ, Zhao CX, Sun C, Li B, Fan BY, Wang X, Li WX, et al: Deferoxamine promotes recovery of traumatic spinal cord injury by inhibiting ferroptosis. Neural Regen Res 14: 532-541, 2019

36. Zhang D, Wang F, Zhai X, Li XH and He XJ: Lithium promotes recovery of neurological function after spinal cord injury by inducing autophagy. Neural Regen Res 13: 2191-2199, 2018.

37. Zhou LY, Song ZF, Zhou LW, Qiu Y, Hu N, Hu Y and Hu X: Protective role of astragalus injection in spinal cord ischemia-reperfusion injury in rats. Neurosciences (Riyadh) 23: 116-121, 2018.

38. Sharma HS: Pathophysiology of blood-spinal cord barrier in traumatic injury and repair. Curr Pharm Des 11: 1353-1389, 2005.

39. Aarabi B, Olexa J, Chryssikos T, Galvagno SM, Hersh DS, Wessell A, Sansur C, Schwartzbauer G, Crandall K et al: Extent of Spinal Cord Decompression in Motor Complete (American Spinal Injury Association Impairment Scale Grades A and B) Traumatic Spinal Cord Injury Patients: Post-Operative Magnetic Resonance Imaging Analysis of Standard Operative Approaches. J Neurotrauma 36: 862-876, 2019.

40. Akhmetzyanova ER, Mukhamedshina YO, Zhuravleva MN, Galieva LR, Kostennikov AA, Garanina EE and Rizvanov AA: Transplantation of microglia in the area of spinal cord injury in an acute period increases tissue sparing, but not functional recovery. Front Cell Neurosci 12: 507, 2018.

41. Aguiar SA, Baker SN, Gant K, Bohorquez J and Thomas CK Spasms after spinal cord injury show low-frequency intermuscular coherence. J Neurophysiol 120: 1765-1771, 2018. 
42. Tang Y, Liu HL, Min LX, Yuan HS, Guo L, Han PB, Lu YX, Zhong JF and Wang DL: Serum and cerebrospinal fluid tau protein level as biomarkers for evaluating acute spinal cord injury severity and motor function outcome. Neural Regen Res 14: 896-902, 2019.

43. Alizadeh A, Santhosh K, Kataria H and Karimi-Abdolrezaee S: Neuregulin-1 positively modulates neuroinflammation and improves functional recovery following traumatic spinal cord injury. J Neurotrauma 35: A32-A32, 2018.

44. Baklaushev VP, Durov OV, Kim SV, Gulaev EV, Gubskiy IL, Konoplyannikov MA, Zabozlaev FG, Zhang C, Agrba VZ, Orlov SV, et al: Development of a motor and somatosensory evoked potentials-guided spinal cord Injury model in non-human primates. J Neurosci Methods 311: 200-214, 2019.

45. Bonizzato M, Pidpruzhnykova G, DiGiovanna J, Shkorbatova P, Pavlova N, Micera S and Courtine G: Brain-controlled modulation of spinal circuits improves recovery from spinal cord injury. Nat Commun 9: 3015, 2018.

46. Burnside ER, De Winter F, Didangelos A, James ND, Andreica EC, Layard-Horsfall H, Muir EM, Verhaagen J and Bradbury EJ: Immune-evasive gene switch enables regulated delivery of chondroitinase after spinal cord injury. Brain 141: 2362-2381, 2018

47. Casper DS, Zmistowski B, Schroeder GD, McKenzie JC, Mangan J, Vatson J, Hilibrand AS, Vaccaro AR and Kepler CK Preinjury patient characteristics and postinjury neurological status are associated with mortality following spinal cord injury. Spine (Phila Pa 1976) 43: 895-899, 2018.

48. David S, Kroner A, Greenhalgh AD, Zarruk JG and Lopez-Vales R: Myeloid cell responses after spinal cord injury. J Neuroimmunol 321: 97-108, 2018.

49. Chhaya SJ, Quiros-Molina D, Tamashiro-Orrego AD, Houle JD and Detloff MR: Exercise-induced changes to the macrophage response in the dorsal root ganglia prevent neuropathic pain after spinal cord injury. J Neurotrauma 36: 877-890, 2019.

50. Chi LY, Yu J, Zhu H, Li XG, Zhu SG and Kindy MS: The dual role of tumor necrosis factor-alpha in the pathophysiology of spinal cord injury. Neurosci Lett 438: 174-179, 2008.

51. Lv RX, Du LL, Zhang LX and Zhang ZQ: Polydatin attenuates spinal cord injury in rats by inhibiting oxidative stress and microglia apoptosis via Nrf2/HO-1 pathway. Life Sci 217: 119-127, 2019.

52. Ziegler G, Grabher P, Thompson A, Altmann D, Hupp M, Ashburner J, Friston K, Weiskopf N, Curt A and Freund P: Progressive neurodegeneration following spinal cord injury Implications for clinical trials. Neurology 90: e1257-e1266, 2018

53. Zhou QS, Xiang HK, Li A, Lin W, Huang Z, Guo J, Wang P, Chi Y, Xiang K, Xu Y, et al: Activating adiponectin signaling with exogenous AdipoRon reduces myelin lipid accumulation and suppresses macrophage recruitment after spinal cord injury. J Neurotrauma 36: 903-918, 2018.

54. Cizkova D, Cubinkova V, Smolek T, Murgoci AN, Danko J, Vdoviakova K, Humenik F, Cizek M, Quanico J, Fournier I and Salzet M: Correction: Cizkova, D., et al. Localized intrathecal delivery of mesenchymal stromal cells conditioned media improves functional recovery in a rat model of contusive spinal cord injury. Int. J. Mol. Sci. 2018, 19, 870. Int J Mol Sci 19: 1942 2018.

55. de Menezes MF, Nicola F, Vital da Silva IR, Vizuete A, Elsner VR, Xavier LL, Gonçalves CAS, Netto CA and Mestriner RG: Glial fibrillary acidic protein levels are associated with global histone $\mathrm{H} 4$ acetylation after spinal cord injury in rats. Neural Regen Res 13: 1945-1952, 2018.

56. Faden AI and Holaday JW: A role for endorphins in the pathophysiology of spinal cord injury. Adv Biochem Psychopharmacol 28 : 435-446, 1981.

57. O'Hare Doig RL, Santhakumar S, Fehily B, Raja S, Solomon T, Bartlett CA, Fitzgerald M and Hodgetts SI: Acute cellular and functional changes with a combinatorial treatment of ion channel inhibitors following spinal cord injury. Front Mol Neurosci 13 , 85: https://doi.org/10.3389/fnmol.2020.00085, 2020.

58. Durdag E, Yildirim Z, Unlu NL, Kale A and Ceviker N: Neuroprotective effects of vigabatrin on spinal cord ischemia-reperfusion injury. World Neurosurg 120: e33-e41, 2018.

59. Dietrich WD: Clinical significance and potential translation of neural regeneration and functional recovery in monkeys after spinal cord injury. Sci China Life Sci 61: 1291-1292, 2018.

60. Olsson Y, Sharma HS, Nyberg F and Westman J: The opioid receptor antagonist naloxone influences the pathophysiology of spinal cord injury. Prog Brain Res 104: 381-399, 1995.
61. Young W, Flamm ES, Demopoulos HB, Tomasula JJ and DeCrescito V: Effect of naloxone on posttraumatic ischemia in experimental spinal contusion. J Neurosurg 55: 209-219, 1981.

62. Yadollahi M, Kashkooe A, Habibpour E and Jamali K: Prevalence and risk factors of spinal trauma and spinal cord injury in a trauma center in Shiraz, Iran. Iran Red Crescent Med J: Feb, 2018 doi: 10.5812/ircmj.14238.

63. Hogan MK, Zhao TY, Kondiles B, Sellers D, Pun SZ and Horner P: Controlled release of thrombin-inhibitor from injectable hydrogel modulates gliosis after spinal cord injury. J Neurotrauma 35: A37-A37, 2018.

64. Huber E, David G, Thompson AJ, Weiskopf N, Mohammadi S and Freund P: Dorsal and ventral horn atrophy is associated with clinical outcome after spinal cord injury. Neurology 90 : e1510-e1522, 2018

65. Huang WH, Bai XS, Stopper L, Catalin B, Cartarozzi LP, Scheller A and Kirchhoff F: During development NG2 glial cells of the spinal cord are restricted to the oligodendrocyte lineage, but generate astrocytes upon acute injury. Neuroscience 385: 154-165, 2018.

66. Hupp M, Pavese C, Bachmann LM, Koller R and Schubert M; EMSCI Study Group: Electrophysiological multimodal assessments improve outcome prediction in traumatic cervical spinal cord injury. J Neurotrauma 35: 2916-2923, 2018.

67. Kaptanoglu E, Okutan O, Akbiyik F, Solaroglu I, Kilinc A and Beskonakli E: Correlation of injury severity and tissue Evans blue content, lipid peroxidation and clinical evaluation in acute spinal cord injury in rats. J Clin Neurosci 11: 879-885, 2004.

68. Irrera N, Arcoraci V, Mannino F, Vermiglio G, Pallio G, Minutoli L, Bagnato G, Anastasi GP, Mazzon E, Bramanti P, et al: Activation of A2A receptor by PDRN reduces neuronal damage and stimulates WNT/ $\beta$-CATENIN driven neurogenesis in spinal cord injury. Front Pharmacol 9: 506, 2018.

69. Huo J, Ma R, Chai X, Liang HJ, Jiang P, Zhu XL, Chen X and Su BX: Inhibiting a spinal cord signaling pathway protects against ischemia injury in rats. J Thorac Cardiovasc Surg 157: 494-503.e1, 2019.

70. Werner $\mathrm{C}$ and Engelhard K: Pathophysiology of traumatic brain injury. Br J Anaesth 99: 4-9, 2007.

71. Li Y, Gu R, Zhu QS and Liu JC: Changes of spinal edema and expression of aquaporin 4 in methylprednisolone-treated rats with spinal cord injury. Ann Clin Lab Sci 48: 453-459, 2018.

72. Jaja B, Jiang F, Badhiwala J, Fehlings MG and Wilson J: Neurological recovery and functional outcomes following acquired infections after acute spinal cord injury. J Neurotrauma 35: A177-A178, 2018.

73. Lanza M, Campolo M, Casili G, Filippone A, Cuzzocrea S and Esposito E: Sodium butyrate exerts neuroprotective effects in spinal cord injury. FASEB J 32: 824, 2018.

74. DeForge D, Nymark J, Lemaire E, Gardner S, Hunt M, Martel L, Curran D and Barbeau H: Effect of 4-aminopyridine on gait in ambulatory spinal cord injuries: A double-blind, placebo-controlled, crossover trial. Spinal Cord 42: 674-685, 2004.

75. Hall ED: Antioxidant therapies for acute spinal cord injury. Neurotherapeutics 8: 152-167, 2011.

76. Wang HJ, Cahoon R, Cahoon EB, Zheng H, Patel KP and Zucker IH: Glutamatergic receptor dysfunction in spinal cord contributes to the exaggerated exercise pressor reflex in heart failure. Am J Physiol Heart Circ Physiol 308: H447-H455, 2015.

77. Winkler T, Sharma HS, Stalberg E, Badgaiyan RD, Gordh T and Westman J: An L-type calcium channel blocker, nimodipine influences trauma induced spinal cord conduction and axonal injury in the rat. Acta Neurochir Suppl 86: 425-432, 2003.

78. Kusuyama K, Tachibana T, Yamanaka H, Okubo M, Yoshiya S and Noguchi K: Upregulation of calcium channel alpha-2-delta-1 subunit in dorsal horn contributes to spinal cord injury-induced tactile allodynia. Spine J 18: 1062-1069, 2018.

79. Chen YM, Wang BL and Zhao H: Thymoquinone reduces spinal cord injury by inhibiting inflammatory response, oxidative stress and apoptosis via PPAR- $\gamma$ and PI3K/Akt pathways. Exp Ther Med 15: 4987-4994, 2018.

80. Damon Y, Kitano Y and Makino M: Analgesic effects of the novel $\alpha_{2} \delta$ ligand mirogabalin in a rat model of spinal cord injury. Pharmazie 73: 659-661, 2018.

81. Chaves RHD, de Souza CC, Furlaneto IP, Teixeira RKC, Oliveira CP, Rodrigues EM, Santos DASD, Silva RC, Penha NEAD and Lima AR: Influence of tramadol on functional recovery of acute spinal cord injury in rats. Acta Cir Bras 33: 1087-1094, 2018 
82. Harada N, Taoka Y and Okajima K: Role of prostacyclin in the development of compression trauma-induced spinal cord injury in rats. J Neurotrauma 23: 1739-1749, 2006.

83. Sohn S: Ursodeoxycholic acid inhibits inflammatory responses and promotes functional recovery after spinal cord injury in rats. J Neurotrauma 35: A172-A172, 2018

84.Pallottie A, Ratnayake A, Ni L, Acioglu C, Li L, Mirabelli E, Heary RF and Elkabes S: A toll-like receptor 9 antagonist restores below-level glial glutamate transporter expression in the dorsal horn following spinal cord injury. Sci Rep 8: 8723, 2018.

85. Cai J, Sun Y, Yin Z, Wang D, Shi K, Fu Y, Cao X and Ge Y: Analysis of FK506-mediated functional recovery and neuroprotection in a rat model of spinal cord injury indicates that EGF is modulated in astrocytes. Exp Ther Med 16: 501-510, 2018.

86. Kim YH, Ha KY and Kim SI: Spinal cord injury and related clinical trials. Clin Orthop Surg 9: 1-9, 2017.

87. Mori E, Ueta T, Maeda T, Ideta R, Yugué I, Kawano O and Shiba K: Sequential neurological improvements after conservative treatment in patients with complete motor paralysis caused by cervical spinal cord injury without bone and disc injury. J Neurosurg Spine 29: 1-9, 2018.

88. Chen S, Ye J, Chen X, Shi J, Wu W, Lin W, Lin W, Li Y, $\mathrm{Fu} \mathrm{H}$ and Li S: Valproic acid attenuates traumatic spinal cord injury-induced inflammation via STAT1 and NF- $\kappa$ B pathway dependent of HDAC3. J Neuroinflammation 15: 150, 2018.

89. Mongardon N, Kohlhauer M, Lidouren F, Barretto M, Micheau P, Adam C, Dhonneur G, Ghaleh B and Tissier R: Targeted temperature management with total liquid ventilation after ischemic spinal cord injury. Ann Thorac Surg 106: 1797-1803, 2018

90. Chang MC: Spinal Cord injury by direct damage during CT-Guided C7 transforaminal epidural steroid injection. Am J Phys Med Rehabil 97: e62-e64, 2018.

91. Sámano C and Nistri A: Mechanism of neuroprotection against experimental spinal cord injury by riluzole or methylprednisolone. Neurochem Res 44: 200-213, 2019.

92. Ye JC, Qin Y, Tang Y, Ma M, Wang P, Huang L, Yang R, Chen K, Chai C, Wu Y and Shen H: Methylprednisolone inhibits the proliferation of endogenous neural stem cells in nonhuman primates with spinal cord injury. J Neurosurg Spine 29: 199-207, 2018.

93. Chu TH, Cummins K and Stys PK: The triple monoamine re-uptake inhibitor DOV 216,303 promotes functional recovery after spinal cord contusion injury in mice. Neurosci Lett 675 $1-6,2018$

94. Ko MY, Jang EY, Lee JY, Kim SP, Whang SH, Lee BH, Kim HY, Yang CH, Cho HJ and Gwak YS: The role of ventral tegmental area gamma-aminobutyric acid in chronic neuropathic pain after spinal cord injury in rats. J Neurotrauma 35: 1755-1764, 2018.

95. Fehlings MG, Tator $\mathrm{CH}$ and Linden RD: The effect of nimodipine and dextran on axonal function and blood flow following experimental spinal cord injury. J Neurosurg 71: 403-416, 1989.

96. Rosenberg LJ, Teng YD and Wrathall JR: Effects of the sodium channel blocker tetrodotoxin on acute white matter pathology after experimental contusive spinal cord injury. J Neurosci 19 6122-6133, 1999

97. Caglar YS, Demirel A, Dogan I, Huseynov R, Eroglu U, Ozgural O, Cansiz C, Bahadir B, Kilinc MC and Al-Beyati ESM: Effect of riluzole on spinal cord regeneration with hemisection method before injury. World Neurosurg 114: e247-e253, 2018

98. Verma R, Virdi JK, Singh N and Jaggi AS: Animals models of spinal cord contusion injury. Korean J Pain 32: 12-21, 2019.

99. Nagoshi N, Nakashima $\mathrm{H}$ and Fehlings MG: Riluzole as a neuroprotective drug for spinal cord injury: From bench to bedside. Molecules 20: 7775-7789, 2015

100. Fehlings MG, Nakashima H,Nagoshi N, Chow DS, Grossman RG and Kopjar B: Rationale, design and critical end points for the Riluzole in acute spinal cord injury study (RISCIS): A randomized, double-blinded, placebo-controlled parallel multi-center trial. Spinal Cord 54: 8-15, 2016.

101. Grijalva I, García-Pérez A, Díaz J, Aguilar S, Mino D, Santiago-Rodríguez E, Guizar-Sahagún $G$, CastañedaHernández G, Maldonado-Julián H and Madrazo I: High doses of 4-aminopyridine improve functionality in chronic complete spinal cord injury patients with MRI evidence of cord continuity. Arch Med Res 41: 567-575, 2010.

102. Page JC, Park J, Chen Z, Cao P and Shi R: Parallel evaluation of two potassium channel blockers in restoring conduction in mechanical spinal cord injury in rat. J Neurotrauma 35: 1057-1068, 2018.
103. Darlington C: Fampridine acorda therapeutics. Curr Opin Investig Drugs 1: 375-379, 2000.

104. Hayes KC: Impact of extended-release dalfampridine on walking ability in patients with multiple sclerosis. Neuropsychiatr Dis Treat 7: 229-239, 2011.

105. Proks P, Reimann F, Green N, Gribble F and Ashcroft F: Sulfonylurea stimulation of insulin secretion. Diabetes 51 (Suppl 3): S368-S376, 2002.

106. Kurland DB, Tosun C, Pampori A, Karimy JK, Caffes NM, Gerzanich V and Simard JM: Glibenclamide for the treatment of acute CNS injury. Pharmaceuticals (Basel) 6: 1287-1303, 2013.

107. Caffes N, Kurland DB, Gerzanich V and Simard JM: Glibenclamide for the treatment of ischemic and hemorrhagic stroke. Int J Mol Sci 16: 4973-4984, 2015.

108. Popovich PG, Lemeshow S, Gensel JC and Tovar CA: Independent evaluation of the effects of glibenclamide on reducing progressive hemorrhagic necrosis after cervical spinal cord injury. Exp Neurol 233: 615-622, 2012.

109. Simard JM, Tsymbalyuk O, Ivanov A, Ivanova S, Bhatta S, Geng Z, Woo SK and Gerzanich V: Endothelial sulfonylurea receptor 1-regulated NC Ca-ATP channels mediate progressive hemorrhagic necrosis following spinal cord injury. J Clin Invest 117: 2105-2113, 2007.

110. Simard JM, Popovich PG, Tsymbalyuk O and Gerzanich V: Spinal cord injury with unilateral versus bilateral primary hemorrhage-effects of glibenclamide. Exp Neurol 233: 829-835, 2012.

111. Simard JM, Woo SK, Schwartzbauer GT and Gerzanich V: Sulfonylurea receptor 1 in central nervous system injury: A focused review. J Cereb Blood Flow Metab 32: 1699-1717, 2012

112. Cheung V, Hoshide R, Bansal V, Kasper E and Chen CC: Methylprednisolone in the management of spinal cord injuries: Lessons from randomized, controlled trials. Surg Neurol Int 6: $142,2015$.

113. Anwar MA, Al Shehabi TS and Eid AH: Inflammogenesis of secondary spinal cord injury. Front Cell Neurosci 10: 98, 2016.

114. Bracken MB, Shepard MJ, Hellenbrand KG, Collins WF, Leo LS, Freeman DF, Wagner FC, Flamm ES, Eisenberg HM, Goodman JH, et al: Methylprednisolone and neurological function 1 year after spinal cord injury. Results of the national acute spinal cord injury study. J Neurosurg 63: 704-713, 1985.

115. Sayer FT, Kronvall E and Nilsson OG: Methylprednisolone treatment in acute spinal cord injury: The myth challenged through a structured analysis of published literature. Spine J 6: 335-343, 2006

116. Bracken MB, Shepard MJ, Collins WF, Holford TR, Young W, Baskin DS, Eisenberg HM, Flamm E, Leo-Summers L, Maroon J, et al: A randomized, controlled trial of methylprednisolone or naloxone in the treatment of acute spinal-cord injury. Results of the second national acute spinal cord injury study. N Engl J Med 322: 1405-1411, 1990.

117. Bracken MB, Shepard MJ, Holford TR, Leo-Summers L, Aldrich EF, Fazl M, Fehlings M, Herr DL, Hitchon PW, Marshall LF, et al: Administration of methylprednisolone for 24 or 48 hours or tirilazad mesylate for 48 hours in the treatment of acute spinal cord injury. Results of the third national acute spinal cord injury randomized controlled trial. National acute spinal cord injury study. JAMA 277: 1597-1604, 1997.

118. Bracken MB: Steroids for acute spinal cord injury. Cochrane Database Syst Rev 1: CD001046, 2012

119. Bowers CA, Kundu B, Rosenbluth J and Hawryluk GW: Patients with spinal cord injuries favor administration of methylprednisolone. PLoS One 11: e0145991, 2016.

120. Ferrara G, Petrillo MG, Giani T, Marrani E, Filippeschi C, Oranges T, Simonini G and Cimaz R: Clinical use and molecular action of corticosteroids in the pediatric age. Int J Mol Sci 20: 444, 2019.

121. Fehlings MG, Wilson JR, Tetreault LA, Aarabi B, Anderson P, Arnold PM, Brodke DS, Burns AS, Chiba K, Dettori JR, et al: A clinical practice guideline for the management of patients with acute spinal cord injury: Recommendations on the use of methylprednisolone sodium succinate. Global Spine J 7 (Suppl 3): 203S-211S, 2017.

122. Yue JK, Tsolinas RE, Burke JF, Deng H, Upadhyayula PS, Robinson CK, Lee YM, Chan AK, Winkler EA and Dhall SS: Vasopressor support in managing acute spinal cord injury: Current knowledge. J Neurosurg Sci 63: 308-317, 2019.

123. Resnick DK: Updated guidelines for the management of acute cervical spine and spinal cord injury. Neurosurgery 72 (Suppl 2): S1, 2013 . 
124. Mojtahedzadeh M, Taghvaye-Masoumi H, Najafi A, Dianatkhah M, Sharifnia H and Shahrokhi M: Management of hypotension and bradycardia caused by spinal cord injury. The usefulness of midodrine and methylxanthines. Iran J Pharm Res 18: 2131-2135, 2019.

125. Inoue T, Manley GT, Patel N and Whetstone WD: Medical and surgical management after spinal cord injury: Vasopressor usage, early surgerys, and complications. J Neurotrauma 31 : 284-291, 2014

126. Hawryluk G, Whetstone W, Saigal R, Ferguson A, Talbott J, Bresnahan J, Dhall S, Pan J, Beattie M and Manley G: Mean arterial blood pressure correlates with neurological recovery after human spinal cord injury: Analysis of high frequency physiologic data. J Neurotrauma 32: 1958-1967, 2015.

127. Yakovlev AG and Faden AI: Mechanisms of neural cell death Implications for development of neuroprotective treatment strategies. NeuroRx 1: 5-16, 2004.

128. Knoblach SM, Alroy DA, Nikolaeva M, Cernak I, Stoica BA and Faden AI: Caspase inhibitor z-DEVD-fmk attenuates calpain and necrotic cell death in vitro and after traumatic brain injury. J Cereb Blood Flow Metab 24: 1119-1132, 2004

129. Thomas S, Quinn BA, Das SK, Dash R, Emdad L, Dasgupta S Wang XY, Dent P, Reed JC, Pellecchia M, et al: Targeting the Bcl-2 family for cancer therapy. Expert Opin Ther Targets 17: 61-75, 2013

130. Hall ED and Springer JE: Neuroprotection and acute spinal cord injury: A reappraisal. NeuroRx 1: 80-100, 2004.

131. Squair JW, Ruiz I, Phillip AA, Zheng MMZ, Sarafis ZK, Sachdeva R, Gopaul R, Liu J, Tetzlaff W, West CR and Krassioukov AV: Minocycline reduces the severity of autonomic dysreflexia after experimental spinal cord injury. J Neurotrauma 35: 2861-2871, 2018.

132. Zhang H, Xiang Z, Duan X, Jiang JL, Xing YM, Zhu C, Song Q and Yu QR: Antitumor and anti-inflammatory effects of oligosaccharides from Cistanche deserticola extract on spinal cord injury. Int J Biol Macromol 124: 360-367, 2019.

133. Elmore S: Apoptosis: A review of programmed cell death. Toxicol Pathol 35: 495-516, 2007.

134. Scholz R, Sobotka M, Caramoy A, Stempfl T, Moehle C and Langmann T: Minocycline counter-regulates pro-inflammatory microglia responses in the retina and protects from degeneration. J Neuroinflammation 12: 209, 2015.

135. Tikka TM and Koistinaho JE: Minocycline provides neuroprotection against $\mathrm{N}$-methyl-D-aspartate neurotoxicity by inhibiting microglia. J Immunol 166: 7527-7533, 2001.

136. Wells JE, Hurlbert RJ, Fehlings MG and Yong VW: Neuroprotection by minocycline facilitates significant recovery from spinal cord injury in mice. Brain 126 1628-1637, 2003

137. Curtis E, Martin JR, Gabel B, Sidhu N, Rzesiewicz TK, Mandeville R, Van Gorp S, Leerink M, Tadokoro T, Marsala S, et al: A first-in-human, phase I study of neural stem cell transplantation for chronic spinal cord injury. Cell Stem Cell 22: 941-950.e6, 2018.

138. Casha S, Zygun D, McGowan MD, Bains I, Yong VW and Hurlbert RJ: Results of a phase II placebo-controlled randomized trial of minocycline in acute spinal cord injury. Brain 135: 1224-1236, 2012

139. Barros TE Jr, Araujo FF, Higino Lda P, Marcon RM and Cristante AF: The effect of monosialoganglyoside (GM-1) administration in spinal cord injury. Acta Ortop Bras 24: 123-126, 2016.

140. Marcon RM, Cristante AF, de Barros Filho TE, de Oliveira RP and dos Santos GB: Potentializing the effects of GM1 by hyperbaric oxygen therapy in acute experimental spinal cord lesion in rats. Spinal Cord 48: 808-813, 2010.

141. Badhiwala JH, Wilson JR, Kwon BK, Casha S and Fehlings MG: A Review of clinical trials in spinal cord injury including biomarkers. J Neurotrauma 35: 1906-1917, 2018.

142. Geisler FH, Dorsey FC and Coleman WP: Recovery of motor function after spinal-cord injury-a randomized, placebocontrolled trial with GM-1 ganglioside. N Engl J Med 324 1829-1838, 1991.

143. Lee Y, Kim CY, Lee HJ, Kim JG, Han DW, Ko K, Walter J, Chung HM, Schöler HR, Bae YM and Ko K: Two-step generation of oligodendrocyte progenitor cells from mouse fibroblasts for spinal cord injury. Front Cell Neurosci 12: 198, 2018

144. Awad BI, Carmody MA and Steinmetz MP: Potential role of growth factors in the management of spinal cord injury. World Neurosurg 83: 120-131, 2015.
145. Ma DN, Zhang XQ, Ying J, Chen ZJ and Li LX: Efficacy and safety of 9 nonoperative regimens for the treatment of spinal cord injury: A network meta-analysis. Medicine (Baltimore) 96 e8679, 2017

146. Teng YD, Mocchetti I and Wrathall JR: Basic and acidic fibroblast growth factors protect spinal motor neurones in vivo after experimental spinal cord injury. Eur J Neurosci 10: 798-802, 1998.

147. Wu JC, Huang WC, Chen YC, Tu TH, Tsai YA, Huang SF, Huang $\mathrm{HC}$ and Cheng $\mathrm{H}$ : Acidic fibroblast growth factor for repair of human spinal cord injury: A clinical trial. J Neurosurg Spine 15: 216-227, 2011.

148. Gupta V, Mesa RA, Deininger MW, Rivera CE, Sirhan S, Brachmann CB, Collins H, Kawashima J, Xin Y and Verstovsek S: A phase 1/2, open-label study evaluating twice-daily administration of momelotinib in myelofibrosis. Haematologica 102: 94-102, 2017.

149. Clarke WE, Berry M, Smith C, Kent A and Logan A: Coordination of fibroblast growth factor receptor 1 (FGFR1) and fibroblast growth factor-2 (FGF-2) trafficking to nuclei of reactive astrocytes around cerebral lesions in adult rats. Mol Cell Neurosciences 17: 17-30, 2001.

150. Raballo R, Rhee J, Lyn-Cook R, Leckman JF, Schwartz ML and Vaccarino FM: Basic fibroblast growth factor (Fgf2) is necessary for cell proliferation and neurogenesis in the developing cerebral cortex. J Neuroscience 20: 5012-5023, 2000.

151. Zhou Y, Wang Z, Li J, Li X, Xiao J. Fibroblast growth factors in the management of spinal cord injury. J Cell Mol Med 22: 25-37, 2018

152. Ko CC, Tu TH, Wu JC, Huang WC, Tsai YA, Huang SF, Huang $\mathrm{HC}$ and Cheng $\mathrm{H}$ : Functional improvement in chronic human spinal cord injury: Four years after acidic fibroblast growth factor. Sci Rep 8: 12691, 2018.

153. Wu JC, Huang WC, Tsai YA, Chen YC and Cheng H: Nerve repair using acidic fibroblast growth factor in human cervical spinal cord injury: A preliminary phase I clinical study. J Neurosurg Spine 8: 208-214, 2008.

154. Wallner S, Peters S, Pitzer C, Resch H, Bogdahn U and Schneider A: The Granulocyte-colony stimulating factor has a dual role in neuronal and vascular plasticity. Front Cell Dev Biol 3: 48, 2015

155. Nishio Y, Koda M, Kamada T, Someya Y, Kadota R, Mannoji C, Miyashita T, Okada S, Okawa A, Moriya H and Yamazaki M: Granulocyte colony-stimulating factor attenuates neuronal death and promotes functional recovery after spinal cord injury in mice. J Neuropathol Exp Neurol 66: 724-731, 2007.

156. Derakhshanrad N, Saberi H, Yekaninejad MS, Joghataei MT and Sheikhrezaei A: Granulocyte-colony stimulating factor administration for neurological improvement in patients with postrehabilitation chronic incomplete traumatic spinal cord injuries: A double-blind randomized controlled clinical trial. J Neurosurg Spine 29: 97-107, 2018.

157. Koda M, Yamazaki M, Furuya T, Hanaoka H and Grp GSS: Phase 3 clinical trial of granulocyte colony stimulating factor-for acute spinal cord injury (G-Spirit Trial). J Neurotrauma 35: A162-A163, 2018

158. Kitamura K, Iwanami A, Nakamura M, Yamane J, Watanabe K, Suzuki Y, Miyazawa D, Shibata S, Funakoshi H, Miyatake S, et al: Hepatocyte growth factor promotes endogenous repair and functional recovery after spinal cord injury. J Neurosci Res 85: 2332-2342, 2007.

159. Ohta Y, Takenaga M, Hamaguchi A, Ootaki M, Takeba Y, Kobayashi T, Watanabe M, Iiri T and Matsumoto N: Isolation of adipose-derived stem/stromal cells from cryopreserved fat tissue and transplantation into rats with spinal cord injury. Int J Mol Sci 19: 1963, 2018

160. Kitamura K, Fujiyoshi K, Yamane J, Toyota F, Hikishima K, Nomura T, Funakoshi H, Nakamura T, Aoki M, Toyama Y, et al: Human hepatocyte growth factor promotes functional recovery in primates after spinal cord injury. PLoS One 6: e27706, 2011

161. Kitamura K, Nagoshi N, Tsuji O, Matsumoto M, Okano H and Nakamura M: Application of hepatocyte growth factor for acute spinal cord Injury: The road from basic studies to human treatment. Int J Mol Sci 20: 1054, 2019.

162. Dergham P, Ellezam B, Essagian C, Avedissian H, Lubell WD and Mckerracher L: Rho signaling pathway targeted to promote spinal cord repair. J Neurosci 22: 6570-6577, 2002.

163. Siddiqui AM, Khazaei M and Fehlings MG: Translating mechanisms of neuroprotection, regeneration, and repair to treatment of spinal cord injury. Prog Brain Res 218: 15-54, 2015. 
164. Fehlings MG, Theodore N, Harrop J, Maurais G, Kuntz C, Shaffrey CI, Kwon BK, Chapman J, Yee A, Tighe A and McKerracher L: A phase I/IIa clinical trial of a recombinant Rho protein antagonist in acute spinal cord injury. J Neurotrauma 28: 787-796, 2011

165. Gonzenbach RR, Zoerner B, Schnell L, Weinmann O, Mir AK and Schwab ME: Delayed anti-nogo-a antibody application after spinal cord injury shows progressive loss of responsiveness. J Neurotrauma 29: 567-578, 2012.

166.Xing B, Li H, Wang H, Mukhopadhyay D, Fisher D, Gilpin CJ and Li S: RhoA-inhibiting NSAIDs promote axonal myelination after spinal cord injury. Exp Neurol 231: 247-260, 2011

167. Iannitti RG, Napolioni V, Oikonomou V, De Luca A, Galosi C, Pariano M, Massi-Benedetti C, Borghi M, Puccetti M, Lucidi $\mathrm{V}$, et al: IL-1 receptor antagonist ameliorates inflammasome-dependent inflammation in murine and human cystic fibrosis. Nat Commun 7: 10791, 2016.

168. Yiu G and He Z: Glial inhibition of CNS axon regeneration. Nat Rev Neurosci 7: 617-627, 2006.

169. Liebscher T, Schnell L, Schnell D, Scholl J, Schneider R, Gullo M, Fouad K, Mir A, Rausch M, Kindler D, et al: Nogo-A antibody improves regeneration and locomotion of spinal cord-injured rats. Ann Neurol 58: 706-719, 2005.

170. Freund P, Wannier T, Schmidlin E, Bloch J, Mir A, Schwab ME and Rouiller EM: Anti-Nogo-A antibody treatment enhances sprouting of corticospinal axons rostral to a unilateral cervical spinal cord lesion in adult macaque monkey. J Comp Neurol 502: 644-659, 2007.

171. Wiessner C, Bareyre FM, Allegrini PR, Mir AK, Frentzel S, Zurini M, Schnell L, Oertle T and Schwab ME: Anti-Nogo-A antibody infusion 24 hours after experimental stroke improved behavioral outcome and corticospinal plasticity in normotensive and spontaneously hypertensive rats. J Cereb Blood Flow Metab 23: 154-165, 2003.

172. Zörner B and Schwab ME: Anti-Nogo on the go: From animal models to a clinical trial. Ann N Y Acad Sci 1198 (Suppl 1): E22-E34, 2010.

173. Kawakami M: Molecular dissection of cyclosporin A's neuroprotective effect reveals potential therapeutics for ischemic brain injury. Brain Sci 3: 1325-1356, 2013.

174. Liu J, Farmer JD Jr, Lane WS, Friedman J, Weissman I and Schreiber SL: Calcineurin is a common target of cyclophilin-cyclosporin A and FKBP-FK506 complexes. Cell 66: 807-815, 1991

175. Sharkey J and Butcher SP: Immunophilins mediate the neuroprotective effects of FK506 in focal cerebral ischaemia Nature 371: 336-339, 1994.

176. Arii T, Kamiya T, Arii K, Ueda M, Nito C, Katsura KI and Katayama Y: Neuroprotective effect of immunosuppressant FK506 in transient focal ischemia in rat: Therapeutic time window for FK506 in transient focal ischemia. Neurol Res 23 755-760, 2001.

177. Gold BG, Densmore V, Shou W, Matzuk MM and Gordon HS Immunophilin FK506-binding protein 52 (not FK506-binding protein 12) mediates the neurotrophic action of FK506. J Pharmacol Exp Ther 289: 1202-1210, 1999.

178. Kang CB, Hong Y, Dhe-Paganon S and Yoon HS: FKBP family proteins: Immunophilins with versatile biological functions. Neurosignals 16: 318-325, 2008.

179. Jones LL, Oudega M, Bunge MB and Tuszynski MH: Neurotrophic factors, cellular bridges and gene therapy for spinal cord injury. J Physiol 533: 83-89, 2001.

180. Weissmiller AM and Wu C: Current advances in using neurotrophic factors to treat neurodegenerative disorders. Transl Neurodegener 1: 14, 2012.

181. Barakat DJ, Gaglani SM, Neravetla SR, Sanchez AR, Andrade CM, Pressman Y, Puzis R, Garg MS, Bunge MB and Pearse DD: Survival, integration, and axon growth support of glia transplanted into the chronically contused spinal cord. Cell Transplant 14: 225-240, 2005.

182. Jiang DJ, Xu CL and Tsang SH: Revolution in gene medicine therapy and genome surgery. Genes 9: 575, 2018.

183. Boyce VS and Mendell LM: Neurotrophic factors in spinal cord injury. Handb Exp Pharmacol 220: 443-460, 2014.

184. Hodgetts SI and Harvey AR: Neurotrophic factors used to treat spinal cord injury. Vitam Horm 104: 405-457, 2017.

185. Campbell JD and Burnett AL: Neuroprotective and nerve regenerative approaches for treatment of erectile dysfunction after cavernous nerve injury. Int J Mol Sci 18: 1794, 2017.
186. Doll DN, Barr TL and Simpkins JW: Cytokines: Their role in stroke and potential use as biomarkers and therapeutic targets. Aging Dis 5: 294-306, 2014.

187. Emsley HC and Tyrrell PJ: Inflammation and infection in clinical stroke. J Cereb Blood Flow Metab 22: 1399-1419, 2002.

188. Huebner EA and Strittmatter SM: Axon regeneration in the peripheral and central nervous systems. Results Probl Cell Differ 48: 339-351, 2009.

189. Barritt AW, Davies M, Marchand F, Hartley R, Grist J, Yip P, McMahon SB and Bradbury EJ: Chondroitinase ABC promotes sprouting of intact and injured spinal systems after spinal cord injury. J Neurosci 26: 10856-10867, 2006.

190. Caggiano AO, Zimber MP, Ganguly A, Blight AR and Gruskin EA: Chondroitinase ABCI improves locomotion and bladder function following contusion injury of the rat spinal cord. J Neurotrauma 22: 226-239, 2005

191. Iaci JF, Vecchione AM, Zimber MP and Caggiano AO: Chondroitin sulfate proteoglycans in spinal cord contusion injury and the effects of chondroitinase treatment. J Neurotrauma 24 : $1743-1759,2007$

192. Iseda T, Okuda T, Kane-Goldsmith N, Mathew M, Ahmed S, Chang YW, Young W and Grumet M: Single, high-dose intraspinal injection of chondroitinase reduces glycosaminoglycans in injured spinal cord and promotes corticospinal axonal regrowth after hemisection but not contusion. J Neurotrauma 25: 334-349, 2008 .

193. Kwok JC, Afshari F, Garcia-Alias G and Fawcett JW: Proteoglycans in the central nervous system: Plasticity, regeneration and their stimulation with chondroitinase ABC. Restor Neurol Neurosci 26: 131-145, 2008

194. Grimpe B and Silver J: A novel DNA enzyme reduces glycosaminoglycan chains in the glial scar and allows microtransplanted dorsal root ganglia axons to regenerate beyond lesions in the spinal cord. J Neurosci 24: 1393-1397, 2004.

195. McRae PA and Porter BE: The perineuronal net component of the extracellular matrix in plasticity and epilepsy. Neurochem Int 61: 963-972, 2012.

196. Moon LD, Asher RA, Rhodes KE and Fawcett JW: Regeneration of CNS axons back to their target following treatment of adult rat brain with chondroitinase ABC. Nat Neurosci 4: 465-466, 2001.

197. Bradbury EJ, Moon LD, Popat RJ, King VR, Bennett GS, Patel PN, Fawcett JW and McMahon SB: Chondroitinase ABC promotes functional recovery after spinal cord injury. Nature 416: 636-640, 2002.

198. Wang D, Ichiyama RM, Zhao R, Andrews MR and Fawcett JW: Chondroitinase combined with rehabilitation promotes recovery of forelimb function in rats with chronic spinal cord injury. J Neurosci 31: 9332-9344, 2011.

199. Hu HZ, Granger N, Pai SB, Bellamkonda RV and Jeffery ND: Therapeutic efficacy of microtube-embedded chondroitinase $\mathrm{ABC}$ in a canine clinical model of spinal cord injury. Brain 141: 1017-1027, 2018

200. Rosenzweig ES, Courtine G, Jindrich DL, Brock JH, Ferguson AR, Strand SC, Nout YS, Roy RR, Miller DM, Beattie MS, et al: Extensive spontaneous plasticity of corticospinal projections after primate spinal cord injury. Nat Neurosci 13: 1505-1510, 2010.

201. Lawrence DG and Kuypers HG: The functional organization of the motor system in the monkey. I. The effects of bilateral pyramidal lesions. Brain 91: 1-14, 1968

202. Nout YS, Ferguson AR, Strand SC, Moseanko R, Hawbecker S, Zdunowski S, Nielson JL, Roy RR, Zhong H, Rosenzweig ES, et al: Methods for functional assessment after C7 spinal cord hemisection in the rhesus monkey. Neurorehabil Neural Repair 26: 556-569, 2012.

203. Jefferson SC, Tester NJ and Howland DR: Chondroitinase ABC promotes recovery of adaptive limb movements and enhances axonal growth caudal to a spinal hemisection. J Neuroscience 31: $5710-5720,2011$

204. Ma R, Liu X, Clark J, Williams GM and Doi SA: The impact of acupuncture on neurological recovery in spinal cord injury: A systematic review and Meta-analysis. J Neurotrauma 32: 1943-1957, 2015

205. Wang J, Zhai Y, Wu J, Zhao S, Zhou J and Liu Z: Acupuncture for chronic urinary retention due to spinal cord injury: A systematic review. Evid Based Complement Alternat Med 2016: 9245186, 2016. 
206. Dyson-Hudson TA, Kadar P, LaFountaine M, Emmons R, Kirshblum SC, Tulsky D and Komaroff E: Acupuncture for chronic shoulder pain in persons with spinal cord injury: A small-scale clinical trial. Arch Phys Med Rehabil 88: 1276-1283, 2007.

207. Liu F, Zou Y, Liu S, Liu J and Wang T: Electro-acupuncture treatment improves neurological function associated with downregulation of PDGF and inhibition of astrogliosis in rats with spinal cord transection. J Mol Neurosci 51: 629-635, 2013.

208. Tu WZ, Jiang SH, Zhang L, Li SS, Gu PP, He R, Hu J, Gao LP and Sun QS: Electro-acupuncture at Governor Vessel improves neurological function in rats with spinal cord injury. Chin J Integr Med: Jul 31, 2017 (Epub ahead of print). doi: $10.1007 / \mathrm{s} 11655-017-2968-9$

209. Lovas J, Tran Y, Middleton J, Bartrop R, Moore N and Craig A: Managing pain and fatigue in people with spinal cord injury: A randomized controlled trial feasibility study examining the efficacy of massage therapy. Spinal Cord 55: 162-166, 2017.

210. Diego MA, Field T, Hernandez-Reif M, Hart S, Brucker B, Field $\mathrm{T}$ and Burman I: Spinal cord patients benefit from massage therapy. Int J Neurosci 112: 133-142, 2002.

211. Field T: Massage therapy research review. Complement Ther Clin Pract 24: 19-31, 2016.

212. Moyer CA, Rounds J and Hannum JW: A meta-analysis of massage therapy research. Psychol Bull 130: 3-18, 2004

213. Field T, Hernandez-Reif M, Diego M, Schanberg S and Kuhn C: Cortisol decreases and serotonin and dopamine increase following massage therapy. Int J Neurosci 115: 1397-1413, 2005.

214. Campeau MP, Gaboriault R, Drapeau M, Van Nguyen T, Roy I, Fortin B, Marois M and Nguyen-Tân PF: Impact of massage therapy on anxiety levels in patients undergoing radiation therapy: Randomized controlled trial. J Soc Integr Oncol 5: 133-138, 2007.

215. Sliwinski MM, Smith R and Wood A: Spinal cord injury rehabilitation patient and physical therapist perspective: A pilot study. Spinal Cord Ser Cases 2: 15036, 2016.

216. DeSantana JM, Walsh DM, Vance C, Rakel BA and Sluka KA: Effectiveness of transcutaneous electrical nerve stimulation for treatment of hyperalgesia and pain. Curr Rheumatol Rep 10: 492-499, 2008.

217. Gozani SN: Remote analgesic effects of conventional transcutaneous electrical nerve stimulation: A scientific and clinical review with a focus on chronic pain. J Pain Res 12: 3185-3201, 2019.

218. Gibson W, Wand BM and O'Connell NE: Transcutaneous electrical nerve stimulation (TENS) for neuropathic pain in adults. Cochrane Database Syst Rev 9: CD011976, 2017.

219. Bi X, Lv H, Chen BL, Li X and Wang XQ: Effects of transcutaneous electrical nerve stimulation on pain in patients with spinal cord injury: A randomized controlled trial. J Phys Ther Sci 27: 23-25, 2015.

220. Dailey DL, Rakel BA, Vance CG, Liebano RE, Amrit AS, Bush HM, Lee KS, Lee JE and Sluka KA: Transcutaneous electrical nerve stimulation reduces pain, fatigue and hyperalgesia while restoring central inhibition in primary fibromyalgia. Pain 154: 2554-2562, 2013.
221. Vance CG, Dailey DL, Rakel BA and Sluka KA: Using TENS for pain control: The state of the evidence. Pain Manage 4: 197-209, 2014.

222.Zeb A, Arsh A, Bahadur S and Ilyas SM: Effectiveness of transcutaneous electrical nerve stimulation in management of neuropathic pain in patients with post traumatic incomplete spinal cord injuries. Pak J Med Sci 34: 1177-1180, 2018.

223. Hagen EM and Rekand T: Management of neuropathic pain associated with spinal cord injury. Pain Ther 4: 51-65, 2015

224. Guanziroli E, Cazzaniga M, Colombo L, Basilico S, Legnani G and Molteni F: Assistive powered exoskeleton for complete spinal cord injury: Correlations between walking ability and exoskeleton control. Eur J Phys Rehabil Med 55: 209-216, 2019.

225. Louie DR, Eng JJ and Lam T: Gait speed using powered robotic exoskeletons after spinal cord injury: A systematic review and correlational study. J Neuroeng Rehabil 12: 82, 2015.

226. Miller LE, Zimmermann AK and Herbert WG: Clinical effectiveness and safety of powered exoskeleton-assisted walking in patients with spinal cord injury: Systematic review with meta-analysis. Med Devices 9: 455-466, 2016.

227. Lajeunesse V, Vincent C, Routhier F, Careau E and Michaud F: Exoskeletons' design and usefulness evidence according to a systematic review of lower limb exoskeletons used for functional mobility by people with spinal cord injury. Disabil Rehabil Assist Technol 11: 535-547, 2016.

228. Nas K, Yazmalar L, Sah V, Aydın A and Önes K: Rehabilitation of spinal cord injuries. World J Orthopedics 6: 8-16, 2015.

229. GrasmückeD,Zieriacks A, Jansen O,FisahnC, Sczesny-Kaiser M, Wessling M, Meindl RC, Schildhauer TA and Aach M: Against the odds: What to expect in rehabilitation of chronic spinal cord injury with a neurologically controlled Hybrid Assistive Limb exoskeleton. A subgroup analysis of 55 patients according to age and lesion level. Neurosurg Focus 42: E15, 2017.

230. Karelis AD, Carvalho LP, Castillo MJ, Gagnon DH and Aubertin-Leheudre M: Effect on body composition and bone mineral density of walking with a robotic exoskeleton in adults with chronic spinal cord injury. J Rehabil Med 49: 84-87, 2017.

231. Gorgey AS, Wade R, Sumrell R, Villadelgado L, Khalil RE and Lavis T: Exoskeleton training may improve level of physical activity after spinal cord injury: A case series. Top Spinal Cord Inj Rehabil 23: 245-255, 2017.

232. Cirnigliaro CM, Myslinski MJ, La Fountaine MF, Kirshblum SC, Forrest GF and Bauman WA: Bone loss at the distal femur and proximal tibia in persons with spinal cord injury: Imaging approaches, risk of fracture, and potential treatment options. Osteoporosis Int 28: 747-765, 2017.

233. Escalona MJ, Brosseau R, Vermette M, Comtois AS, Duclos C, Aubertin-Leheudre $\mathrm{M}$ and Gagnon DH: Cardiorespiratory demand and rate of perceived exertion during overground walking with a robotic exoskeleton in long-term manual wheelchair users with chronic spinal cord injury: A cross-sectional study. Ann Phys Rehabil Med 61: 215-223, 2018.

This work is licensed under a Creative Common Attribution-NonCommercial-NoDerivatives 4.0 International (CC BY-NC-ND 4.0) License. 